\title{
KChIP-Like Auxiliary Subunits of Kv4 Channels Regulate Excitability of Muscle Cells and Control Male Turning Behavior during Mating in Caenorhabditis elegans
}

\author{
Xin Chen, ${ }^{1,2}$ Mei-Yu Ruan, ${ }^{1}$ and Shi-Qing Cai ${ }^{1}$ \\ ${ }^{1}$ Institute of Neuroscience and State Key Laboratory of Neuroscience, Shanghai Institutes for Biological Sciences, Chinese Academy of Sciences, Shanghai \\ 200031, China, and 2University of Chinese Academy of Sciences, Shanghai 200031, P. R. China
}

\begin{abstract}
Voltage-gated Kv4 channels control the excitability of neurons and cardiac myocytes by conducting rapidly activating-inactivating currents. The function of $\mathrm{Kv} 4$ channels is profoundly modulated by $\mathrm{K}^{+}$channel interacting protein (KChIP) soluble auxiliary subunits. However, the in vivo mechanism of the modulation is not fully understood. Here, we identified three C. elegans KChIP-like (ceKChIP) proteins, NCS-4, NCS-5, and NCS-7. All three ceKChIPs alter electrical characteristics of SHL-1, a C. elegans Kv4 channel ortholog, currents by slowing down inactivation kinetics and shifting voltage dependence of activation to more hyperpolarizing potentials. Native SHL-1 current is completely abolished in cultured myocytes of Triple KO worms in which all three ceKChIP genes are deleted. Reexpression of NCS-4 partially restored expression of functional SHL-1 channels, whereas NCS-4(efm), a NCS-4 mutant with impaired Ca ${ }^{2+}$-binding ability, only enhanced expression of SHL-1 proteins, but failed to transport them from the Golgi apparatus to the cell membrane in body wall muscles of Triple KO worms. Moreover, translational reporter revealed that NCS-4 assembles with SHL- $1 \mathrm{~K}^{+}$channels in male diagonal muscles. Deletion of either $n c s-4$ or $s h l-1$ significantly impairs male turning, a behavior controlled by diagonal muscles during mating. The phenotype of the ncs- 4 null mutant could be rescued by reexpression of NCS-4, but not NCS-4(efm), further emphasizing the importance of $\mathrm{Ca}^{2+}$ binding to ceKChIPs in regulating native SHL-1 channel function. Together, these data reveal an evolutionarily conserved mechanism underlying the regulation of Kv4 channels by KChIPs and unravel critical roles of ceKChIPs in regulating muscle cell excitability and animal behavior in C. elegans.
\end{abstract}

Key words: C. elegans; calcium binding; KChIP; male mating; potassium channel; turing behavior

\section{Introduction}

Native voltage-gated $\mathrm{K}^{+}$channels $(\mathrm{Kv})$ are often complexes composed of pore-forming $\alpha$-subunits and auxiliary subunits. Auxiliary subunits modulate a wide range of $\mathrm{Kv}$ channel properties, including electrical and pharmacological characteristics, trafficking to the plasma membrane, and turnover of the channels ( $\mathrm{Li}$ et al., 2006; Cai et al., 2007; Pongs and Schwarz, 2010). The importance of accessory subunits is also validated by the facts that mutations of these genes result in human diseases such as hypertension, epilepsy, Long QT syndrome, and periodic paralysis (Abbott et al., 1999; Sesti et al., 2000; Abbott et al., 2001; Kuo et al., 2001; Brenner et al., 2005; Schulte et al., 2006; Roepke et al., 2009).

\footnotetext{
Received Aug. 16, 2014; revised Dec. 2, 2014; accepted Dec. 3, 2014.

Author contributions: X.C., M.-Y.R., and S.-Q.C. designed research; X.C. and M.-Y.R. performed research; X.C., M.-Y.R., and S.-Q.C. analyzed data; S.-Q.C. wrote the paper.

This work was supported by National Natural Science Foundation of China (Grant 31471149), and CAS Hundred Talent Program (S.-Q.C.). We thank Drs. Federico Sesti and Ying Liu for critical reading of this manuscript, Dr. S. Mitani (Tokyo Women's Medical University School of Medicine) and the C. elegans Genetics Center (funded by National Institutes of Health Grant P40 0D010440) for providing us strains, and Dr. Zu0-Ren Wang for mCD8 cDNA. The authors declare no competing financial interests.

Correspondence should be addressed to Shi-Qing Cai, 320 Yueyang Road, Biological Research Building, Room 505A, Shanghai, People's Republic of China 200031. E-mail: sqcai@ion.ac.cn.

DOI:10.1523/JNEUROSCI.3429-14.2015

Copyright $\odot 2015$ the authors $\quad 0270-6474 / 15 / 351880-12 \$ 15.00 / 0$
}

The majority of genes encoding $\mathrm{K}^{+}$channels are conserved between $C$. elegans and mammals. Voltage-gated $\mathrm{K}^{+}$channels, such as ether-a-go-go (EAG)-type EGL-2, ERG-type (EAG related) UNC-103, Shaw-type EGL-36 and KHT-1, Shab-type KVS-1, and an inward rectifying channel EXP-2, regulate many behaviors including locomotion, defecation, pharyngeal pumping, egg-laying, chemotaxis, habituation, and male mating in C. elegans (Elkes et al., 1997; Johnstone et al., 1997; Davis et al., 1999; Weinshenker et al., 1999; Bianchi et al., 2003; Garcia and Sternberg, 2003; Cai et al., 2009). However, it is unclear whether native $\mathrm{K}^{+}$channels in C. elegans, physiologically similar to those in mammals, also possess conserved auxiliary subunits. The existence of ancillary subunits would provide the possibility of using C. elegans animal model to understand the underlying mechanism of interaction between $\alpha$ and auxiliary subunits of potassium channels and the physiological roles of ancillary subunits in modulating cell excitability. To date only KCNE-like subunits named MPS-1-4 have been identified to assemble with two $\mathrm{K}^{+}$channels in $C$. elegans, KVS-1 and KHT-1, which regulate sensory and learning behaviors, respectively (Bianchi et al., 2003; Cai et al., 2005; Park et al., 2005; Cai et al., 2009).

$\mathrm{K}^{+}$channel interacting proteins (KChIPs) are soluble auxiliary subunits of $\mathrm{Kv} 4 \alpha$-subunits, the rapidly activating/inactivat- 
ing (A-type) voltage-gated $\mathrm{K}^{+}$channels that control excitability of neurons and cardiac myocytes (Kuo et al., 2001; Birnbaum et al., 2004; Rhodes et al., 2004; Thomsen et al., 2009; Wang et al., 2013). KChIPs belong to the neuronal $\mathrm{Ca}^{2+}$ sensor superfamily that exhibits four $\mathrm{Ca}^{2+}$-binding EF hand motifs. Previous studies in heterologous expressing systems have demonstrated that KChIPs alter Kv4.2 current properties including activation and inactivation kinetics, as well as trafficking of the channels (An et al., 2000; Holmqvist et al., 2001; Shibata et al., 2003; Jerng et al., 2005; Tang et al., 2013). The modulation is dependent on $\mathrm{Ca}^{2+}$ binding to the EF hands of KChIPs (An et al., 2000; Patel et al., 2002; Pioletti et al., 2006). In this study, we identified three KChIP-like neuronal calcium sensor proteins, NCS-4, NCS-5, and NCS-7, in C. elegans. These ceKChIPs regulate muscle cell excitability and animal behaviors by controlling the generation of SHL-1 channels. We also clarify that $\mathrm{Ca}^{2+}$ binding to ceKChIPs promotes trafficking of SHL-1 proteins at the stage of transporting them from the Golgi apparatus to the cell membrane.

\section{Materials and Methods}

Strains and culture of worms. N2, shl-1(ok1168) and unc-54(e190) were obtained from the Caenorhabditis Genetics Center (CGC). ncs-4(tm4409), $n c s-5$ (tm4951), ncs-7(tm5037) were obtained from the National BioResource Project (NBRP), Japan. All mutant strains were outcrossed with N2 at least five times to clean background before experiments. Triple KO mutant ncs-4(tm4409);ncs-7(tm5037);ncs-5(tm4951) strain was generated by crossing $n c s-4$ (tm4409) with $n c s-7(t m 5037)$ and $n c s-5$ (tm4951) worms. We con-

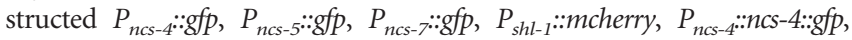
$P_{n c s-4:: n c s-4 ; \text { TripleKO }, P_{n c s-4}:: n c s-4(\text { efm }) ; T r i p l e K O,} P_{n c s-4}:: n c s-4($ efm $) ; n c s-$ 4(tm4409), and $P_{n c s-4}:: n c s-4 ; n c s-4(t m 4409)$-transgenic worms. We also

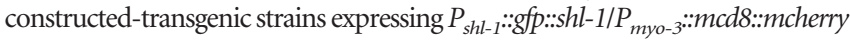

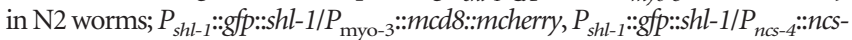
$4 / P_{\text {myo- } 3}:: m c d 8::$ mcherry, $\quad P_{\text {shl }-1}:: g f p:: s h l-1 / P_{n c s-4}:: n c s-4($ efm $) / P_{\text {myo- } 3}:: m c d 8:::$

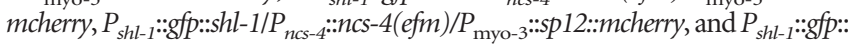

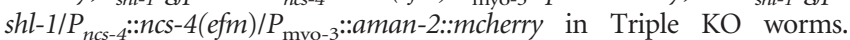
$P_{\text {unc-68 }:: \text { gcamp } 5 / P_{\text {unc-68 }}:: d s r e d 2,} P_{\text {unc-68 }}:$ gcamp5/P $P_{\text {unc-68 }}:$ dsred2;shl-1(ok1168),

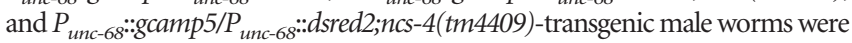
generated for calcium imaging. Worms were cultivated on standard NGM plates with a layer of OP50 Escherichia coli at $20^{\circ} \mathrm{C}$ or $25^{\circ} \mathrm{C}$.

Molecular biology. Three ceKChIP genes, NCS-4, NCS-5, and NCS-7, were cloned by RT-PCR. Primers: NCS-4 gene, forward: $5^{\prime}$-ATGAGCA GCTGGAAACGACGTTCTG-3' and reverse: 5' -TCAACCAGGAAGAAGAGTGTAAAGT-3'; NCS-5 gene, forward: $5^{\prime}$-ATGGGCGGAGCC TCATCAATTGACT- $3^{\prime}$ and reverse: $5^{\prime}$-TTAAAGAGGCTTGGCACA GTTGGCA-3'; NCS-7 gene, forward: 5'-ATGGGTGCATTTTTCACAA ATCACA-3' and reverse: 5'-CTAGATATTTAATAATCCGCTTGAG$3^{\prime}$. The cloned cDNAs were subsequently inserted into pCI-neo vectors. The ncs-4(efm) mutant with abolished $\mathrm{Ca}^{2+}$-binding ability was constructed through site-directed mutagenesis of both aspartic acid and glycine in EF hand motif to alanine following the method described by An et al. (2000). To clone plasmids for coimmunoprecipitation, hemagglutinin (HA) sequence was epitope tagged in the C terminus of NCS-4, NCS-5, and NCS-7. These constructs were then subcloned into the pCIneo vector; c-Myc-tagged SHL-1 plasmid was generated by inserting SHL-1 cDNA into (PCS2+MT) vector. To construct plasmids for expressing in C. elegans, NCS-4 DNA and its $\sim 4 \mathrm{~kb}$ upstream promoters were amplified from N2 C. elegans genomic DNA and inserted into pPD95.75 plasmid. shl-1 DNA and its $\sim 10 \mathrm{~kb}$ promoter were amplified from N2 C. elegans genomic DNA. Primers: shl-1 DNA: forward: 5'-ATGGCTTCGGTGGCGGCGTGGCTGC-3' and reverse: 5'-TTACAGTTGCGATACGCAAATTTTG-3'; shl-1 promoter: forward: $5^{\prime}$ AGATCAAAAGTGGGGACTCTGATGA-3' and reverse: $5^{\prime}$-TCTGAA GAAGACAACGACGACGGAT-3'. To construct $P_{\text {shl-1 }}:: g f p:: s h l-1$ plasmid, green fluorescence protein (GFP) sequence $\left({ }^{2} \mathrm{E} \sim{ }^{237} \mathrm{~K}\right)$ was inserted in the $\mathrm{N}$ terminus of SHL-1 between residues ${ }^{156} \mathrm{E}$ and ${ }^{157} \mathrm{R}$. Next, the corresponding fused cDNA was cloned into pPD95.75 vector. For body-wall muscle specific expression, $\sim 3 \mathrm{~kb}$ myo-3 promoter was amplified from $\mathrm{N} 2$ worm genomic DNA. $m c d 8$ cDNA was a generous gift from Dr. Zuoren Wang; sp12 and aman-2 cDNA were cloned from N2 genome according to methods described previously (Rolls et al., 2002; Poteryaev et al., 2005). $P_{m y o-3}:: m c d 8:: m c h e r r y$-transgenic plasmid was generated by joining $m y o-3$ promoter and mcd8 cDNA in frame with mcherry reporter gene in the pPD95.75 vector. $P_{m y o-3}::$ sp12:: $m$ cherry-transgenic plasmid was generated by joining myo-3 promoter and sp12 cDNA in frame with mcherry

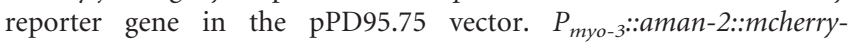
transgenic plasmid was generated by joining myo-3 promoter and gene sequences for 1-82 aa of AMAN-2 in frame with mcherry reporter gene in the pPD95.75 vector. Primers: $m y o-3$ promoter, forward: 5' -TCAGTCT

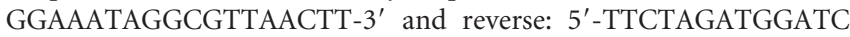
TAGTGGTCGTGG-3'; $m c d 8$ gene, forward: $5^{\prime}$-ATGGCCTCACCGTTG ACCCGCTTTC- $3^{\prime}$ and reverse: $5^{\prime}$-GCGGCTGTGGTAGCAGATGAG AGTG-3'; sp12 gene, forward: 5'-ATGGACGGAATGATTGCAAT GCTCC-3' and reverse: $5^{\prime}$-TTTCGTCTTCTTTGTCTCCTTTTTC-3'; A short region (1-82 aa) of aman-2 gene, forward: $5^{\prime}$-ATGGGAAAA CGCAATTTCTATATTA-3' and reverse: $5^{\prime}$-TTCTTCATCAAAATCTAC CGATTTT-3'. $P_{\text {unc-68 }}::$ gcamp5 and $P_{\text {unc-68 }}::$ dsred 2 expression plasmids were generated by joining $\sim 2.6 \mathrm{~kb}$ of $u n c-68$ upstream promoter as described by Maryon et al. (1998) and full-length gcamp5 or dsred2 cDNA into pPD95.75 vector.

Construction of transgenic animals. All transgenic worms were obtained by microinjecting corresponding plasmids into appropriate strains. The transient transforming lines for $P_{n c s-4}:: n c s-4 ; n c s-4(t m 4409)$ and $P_{n c s-4: n c s-4(e f m) ; n c s-4(t m 4409)}$ were integrated by UV-TMP method (Kage-Nakadai et al., 2012). The progeny were selected by $100 \%$ presence of the marker $\left(P_{\text {myo- } 2:: G F P}\right)$ and the target genes were confirmed via PCR amplification. For each integrated-transgenic strain, two independent lines were used for behavioral analysis after outcrossing four times.

Electrophysiology: patch recording in HEK293T cells. Whole-cell recordings were performed in HEK293T cells after 36-48 h after transfection. Data were recorded with an Axopatch 200B (Axon), filtered at $5 \mathrm{kHz}$, and sampled at $2 \mathrm{kHz}$. Bath solution was composed of the following (in $\mathrm{mm}$ ): $4 \mathrm{KCl}, 100 \mathrm{NaCl}, 10$ HEPES, pH 7.5 with $\mathrm{NaOH}, 1.8 \mathrm{CaCl}_{2}$, and 1.0 $\mathrm{MgCl}_{2}$. Pipette solution contained the following(in mM): $100 \mathrm{KCl}, 10$ HEPES, pH 7.5 with $\mathrm{KOH}, 1.0 \mathrm{MgCl}_{2}, 1.0 \mathrm{CaCl}_{2}$, and $10 \mathrm{EGTA}$, pH 7.5 with $\mathrm{KOH}$. All experiments were recorded at room temperature. Wholecell SHL-1 currents were evoked in response to $400 \mathrm{~ms}$ depolarizing voltage steps to potentials between -80 and $+80 \mathrm{mV}$ (in $10 \mathrm{mV}$ increments) from a holding potential of $-80 \mathrm{mV}$.

Patch recording in C. elegans myocyte culture. Embryonic cells were isolated and cultured as described previously (Strange et al., 2007; Cai and Sesti, 2009). Muscle cells were identified based on distinctive morphology in cell culture and GFP labeling by Pmyo-3::GFP (Christensen et al., 2002). Recordings were performed $3-5 \mathrm{~d}$ after cell plating. Whole-cell patch-clamp recordings were obtained in cultured muscle cells using a method described previously (Santi et al., 2003). Bath solution contained the following (in mM): $145 \mathrm{NaCl}, 5 \mathrm{KCl}, 1 \mathrm{CaCl}_{2}, 5 \mathrm{MgCl}_{2}, 10 \mathrm{HEPES} /$ $\mathrm{NaOH}, \mathrm{pH} 7.50$, and 20 D-glucose. The low- $\mathrm{Ca}^{2+}$ pipette solution consisted of the following (in $\mathrm{mm}$ ): 125 potassium gluconate, $18 \mathrm{KCl}, 0.25$ $\mathrm{CaCl}_{2}, 4.45 \mathrm{MgCl}_{2}, 10$ EGTA/KOH, and $10 \mathrm{HEPES} / \mathrm{KOH}, \mathrm{pH}$ 7.5. The $\mathrm{Ca}^{2+}$-free pipette solution consisted of the following (in $\mathrm{mM}$ ): 125 potassium gluconate, $18 \mathrm{KCl}, 4.7 \mathrm{MgCl}_{2}, 10 \mathrm{D}$-glucose, $10 \mathrm{HEPES} / \mathrm{KOH}, \mathrm{pH}$ 7.5 , and $100 \mu \mathrm{M}$ BAPTA-AM. Whole-cell current traces were obtained by applying voltage steps from -80 to $80 \mathrm{mV}$ in $20 \mathrm{mV}$ increments from a holding potential of $-80 \mathrm{mV}$.

Macroscopic conductance was calculated using the equation $G=$ $I /\left(V-V_{\text {rev }}\right)$, where $I$ is the microscopic current, $V$ is the command voltage, and $V_{\text {rev }}$ is the reversal potential for $\mathrm{K}^{+}$. The $G$ value was normalized to the maximum value and then fitted with a Boltzmann function: $G / G_{\max }=\left[1+\exp \left(-\left(V-V_{0.5}\right) / K\right)\right]^{-1}$, where $V$ is the command voltage and $V_{0.5}$ and $K$ are the midpoint of activation and activation slope factor, respectively. The time course of inactivation was obtained by fitting macroscopic currents recorded from both HEK293T cell and cultured myocytes to a single-exponential function.

Coimmunoprecipitation. Human embryonic kidney-293 T (HEK293T) cells were cultured in DMEM supplemented with $5 \%$ fetal bovine serum, $1 \%$ penicillin/streptomycin (Invitrogen) in a $5 \% \mathrm{CO}_{2}$ incubator at $37^{\circ} \mathrm{C}$. 
A

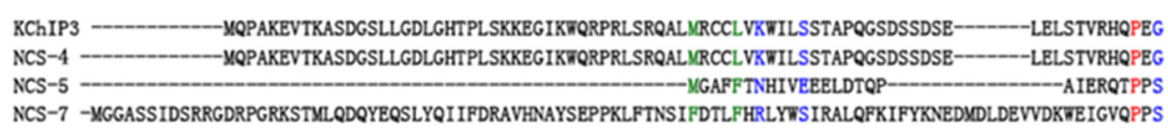

KChIP3 LDQLQAQTKFTKKELQSLYRGFKNECPTGLVDEDTFK-LIYAQPFPQGDATTYAHFLFNAFDADGNGAIHFEDFVVGLSILLRGTVHEKLKWAFNLY NCS-4 LDQLQAQTKFTKKELOSLYRGFKNECTGLVDEDTFK-LIYAQFFPQGDATTYAHFLFNAFDADGNGAIHFEDFVVGLSILLRGTVHEKLKWAFNLY NCS-5 IDYLIEITNFSKREICQLYRSFKELWPIGTVDLEQFQ-LIYASIFPNGDSKGYAELVFKNIDQNRVGTVTFLDFITNYSKIAKGTLDERLDFIFTLY NCS-7 LEQLTQRTQFSPKसIKYYAKFKNESPTGKYKEEEFRNLLASIIAPEKATDOYISRLFTAFAGVDKKTITFENLLDSLSHVQPQTAETNAKNTMRLI

KChIP3 DINKDG-YITKEEVI.AIYKSIYDYYGG-RHTYPILREDAPAEHVERFFEKYDRNQDGVTIEEFLEACOKDENIYSSYQLFENYINCS-4 DINKDG-YITKEEVC.AIMKSIYDUQUG-RHTYPILREDAPAEHVERFFEKXDRNQDGVVTIEEFLEACOKDENIXSSYQLFENVI NCS-5 DTNRCG-FLAYNEIFHVVKSYYOYOD-SSLKPAVLATICROHVKIVFKNLNIANNGKVSKAEFLORCRSDSDILASYELFGSFSSGLLNI- -NCS-7 TGGGEGDCFGYSAFLDFTQSVFOLNEGKSGGEEINKESVQQRATKIFAELDCDRDGLVTYDDUIRFFOKNNDSIGFTPVSPAPNGFANCAKPL

B $P_{n c s-4: \because g f p}$

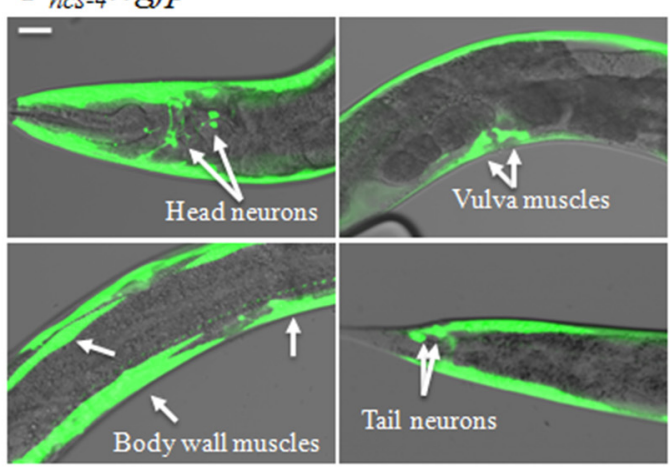

C $P_{n c s-5: \because g f p}$

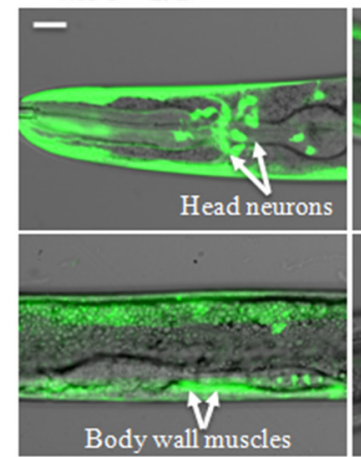

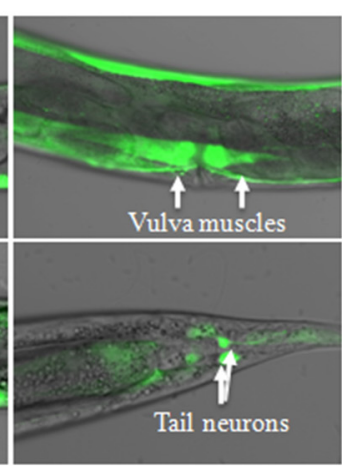

D
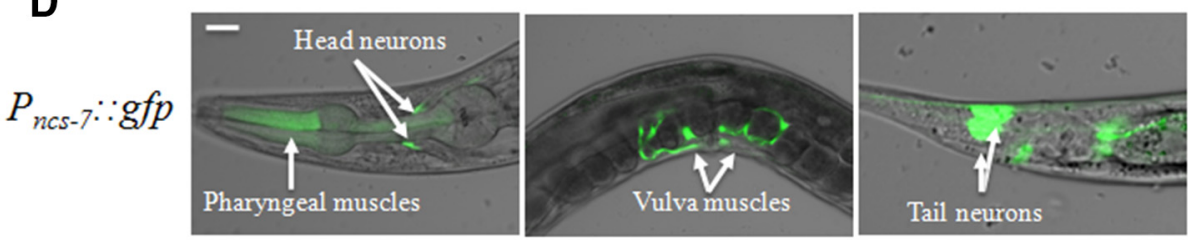

Figure 1. Expression pattern of the ceKChIP Proteins NCS-4, NCS-5, and NCS-7. A, ceKChIP protein sequences and alignment with human KChIP3. NCS-4, NCS-5, and NCS-7 show 36\%, 26\%, and $38 \%$ identity with $\mathrm{KChIP3}$, respectively. The red, green, and blue colors indicate identical, strongly, and weakly similar residues, respectively. Sequence alignment was obtained by ClustalW analysis. $B$, Fluorescent microscopy images taken from $P_{n c-4}:$ : gfp-transgenic worms. White arrows indicate head neurons (left, top), body wall muscles (left, bottom), vulva muscles (right, top), and tail neurons (right, bottom). C, Expression pattern of NCS-5 in $P_{n c-5}::$ :gfp-transgenic worms. White arrows indicate head neurons (left, top), body wall muscles (left, bottom), vulva muscles (right, top),

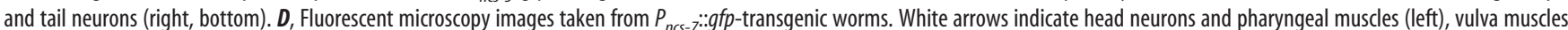
(middle) and tail neurons (right). Scale bars, $20 \mu \mathrm{m}$.

cDNAs were transfected using Lipofectamine 2000 (Invitrogen) and cells were harvested $48 \mathrm{~h}$ after transfection. The transfected cells were lysed in $1 \%$ (v/v) NP-40, 50 mм Tris-Cl, pH 7.4, $150 \mathrm{~mm} \mathrm{NaCl,} 1$ mм NaF, $1 \mathrm{~mm}$ PMSF, and protease inhibitor (Roche). The supernatants of cell lysates were incubated with c-Myc antibody (Sigma) for $3 \mathrm{~h}$ at $4^{\circ} \mathrm{C}$ and then immunoprecipitated with protein $\mathrm{A} / \mathrm{G}$ Plus agarose (Pierce) for $3 \mathrm{~h}$ at $4^{\circ} \mathrm{C}$. Immune complexes were separated on $12.5 \%$ SDS-PAGE gels and probed with anti-HA (Roche) and anti-c-Myc (Sigma) antibodies, respectively.

Silver staining and mass spectrometry. Transgenic $P_{n c s-4}:: n c s-4:: g f p$ and $P_{n c s-4}:: g f p$ worms were raised synchronously at $25^{\circ} \mathrm{C}$. The worms were collected and lysed with buffer containing 50 mu Tris-Cl, pH 7.4, $150 \mathrm{~mm}$ $\mathrm{NaCl}, 1 \mathrm{~mm} \mathrm{NaF}, 1 \mathrm{~mm}$ PMSF, protease inhibitor (Roche), and 1\% (w/v) $N$-dodecyl $\beta$-D-maltoside (Sigma) at $4^{\circ} \mathrm{C}$ for $1 \mathrm{~h}$. The lysate was cleared at $40,000 \times g$ for $40 \mathrm{~min}$ and the supernatant was collected. GFP-tagged NCS-4 was immunoprecipitated using GFP-Trap resin (Chromotek) at $4^{\circ} \mathrm{C}$ for $1 \mathrm{~h}$. Immune complexes were separated on 15\% SDS-PAGE gels and visualized by silver staining. Proteins of immunoprecipitated complexes were then identified by tandem mass spectrometry.

Thrashing assay. Age-matched young adult N2, shl-1(ok1168), ncs4(tm4409), ncs-5(tm4951), and ncs-4(tm4409);ncs-7(tm5037);ncs5(tm4951) (Triple KO mutant) hermaphrodites were examined individually in a drop of M9 buffer for 1 min. Body bends were defined as a change in the direction of bending in the middle of the body. At least 20 animals per strain per assay were counted.
Mating efficiency tests. Mating behavior of N2, shl-1(ok1168), ncs4(tm4409), ncs-5(tm4951), shl-1(ok1168);ncs-4(tm4409), and Triple KO mutant males was conducted as described previously (Yin et al., 2014) with some modifications. Briefly, 1 male of each strain together with two $\mathrm{N} 2$ hermaphrodites were placed on a $3.5 \mathrm{~cm}$ NGM plate seeded with 5 -mm-diameter lawn (10 $\mu \mathrm{l}$ of OP50 was spotted onto NGM plate, allowing to grow for $\sim 1$ day). Males were picked out $24 \mathrm{~h}$ later and mating efficiency was scored $3 \mathrm{~d}$ later. Mating efficiency was scored by calculating the ratio of successful mating plates to total plates. Males of each strain were placed with young adult unc-54(e190) hermaphrodites to record mating processes via a microscopic camera. For turning behavior, only the first attempt was counted and the percentage of successful turning was calculated as the number of successful turning males divided by the total number of tested males. At least 20 males per genotype were analyzed. All behavioral assays were performed without knowing the worms' genotype.

Calcium imaging. To monitor the activity of diagonal muscles, the $\mathrm{Ca}^{2+}$ indicator G CaMP5 (Akerboom et al., 2012) and DsRed2 were expressed in diagonal muscles of male worms by unc- 68 upstream promoter (Maryon et al., 1998). To record the turning behavior in male mating, a young adult transgenic male of each strain was placed together with young adult unc-54(e190) hermaphrodites in 2-mm-thick NGM plate with a very thin layer of bacteria OP50. Images were captured through Nikon A1R laser scanning confocal imaging system at $2 \mathrm{~Hz}$. G CaMP5 and DsRed 2 were excited at 488 and $543 \mathrm{~nm}$, respectively. A $4 \times$ 
A

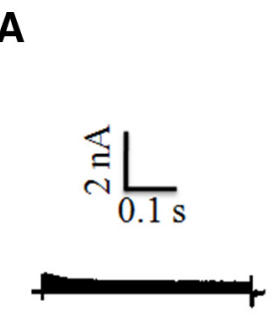

Endogenous current

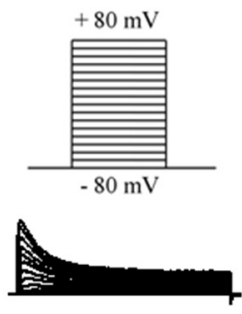

SHL-1

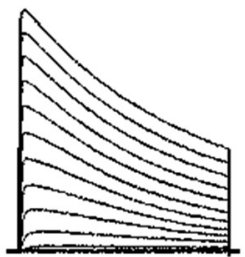

SHL-1+NCS-4

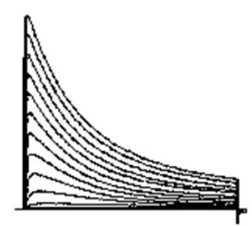

SHL-1+NCS-5

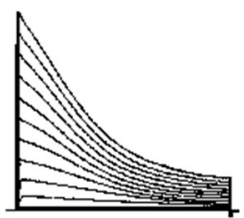

SHL-1+NCS-7
B

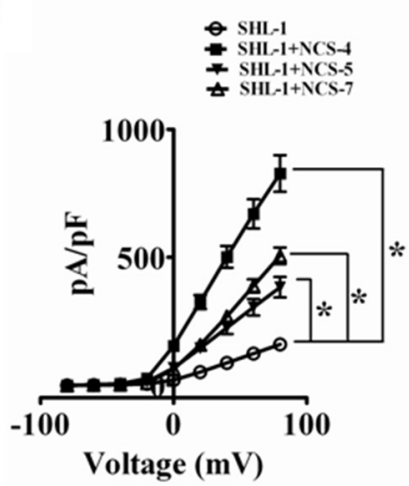

C

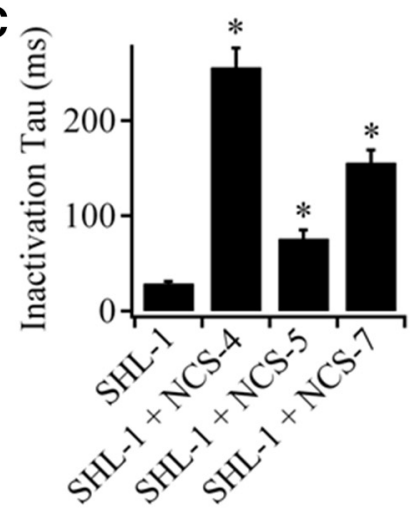

D

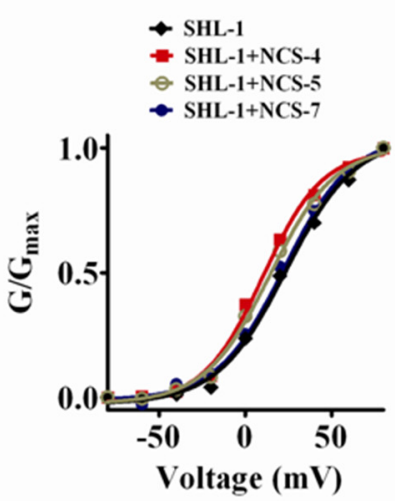

Figure 2. ceKChIPs modulate the function of SHL-1 channels in HEK293T cells. A, Representative whole-cell currents from cells mock-transfected, transfected with SHL-1 alone, or transfected with NCS-4, NCS-5, and NCS-7, respectively. Currents were elicited by voltage jumps from $-80 \mathrm{mV}$ to $+80 \mathrm{mV}$ in $10 \mathrm{mV}$ increments, filtered at $5.0 \mathrm{kHz}$, and sampled at $2.0 \mathrm{kHz}$. Voltage protocol is shown above graph for SHL-1 alone. B, Peak current density-voltage $(\sigma-V)$ relationships for $\mathrm{K}^{+}$channel formed by SHL-1alone $(n=35$ cells), SHL-1/NCS-4 $(n=16$ cells), SHL-1/NCS-5 $(n=19$ cells), and SHL-1/NCS-7 ( $n=25$ cells). Peak current densities were obtained by dividing peak currents at corresponding voltage by the cell capacitance. Mean value of the HEK293T cell capacitance was 17.0, 15.3, 17.4, and 16.7 pF for SHL-1 alone, SHL-1/NCS-4, SHL-1/NCS-5, and SHL-1/NCS-7, respectively. C, Inactivation time constants for currents elicited by SHL-1alone, SHL-1/NCS-4, SHL-1/NCS-5, and SHL-1/NCS-7 at $+80 \mathrm{mV}$. The time constants were calculated by fitting macroscopic currents to a single exponential function, $I_{0}+I_{1} \exp (-t / \tau)$. $D, G / G_{\text {Max }}$ relationships for SHL-1alone, SHL-1/NCS-4, SHL-1/NCS-5, and SHL-1/NCS-7. The theoretical lines were calculated by fitting each curve to the Boltzmann function. Data shown are mean \pm SEM. $n=3$ experiments. ${ }^{*} p<0.001$ (unpaired Student's $t$ test).

objective lens in conjunction with a $5 \times$ zoom was used to acquire images of $\mathrm{Ca}^{2+}$ transient for $\sim 1$ min for each worms. The ratio of G CaMP5/ DsRed2 fluorescence of diagonal muscles in image stacks was calculated by Nikon A1R fluorescence ROI statistics software. The value of $G$ CaMP5/DsRed2 in diagonal muscles of the same male moving alone (without hermaphrodite) was regarded as $R_{0}$.

\section{Results}

\section{Cloning a family of KChIP proteins in C. elegans}

We blasted human KChIP3 amino acid sequence against the $C$. elegans protein database to identify putative KChIPs orthologs in C. elegans. This analysis led us to identify three neuronal $\mathrm{Ca}^{2+}$ sensor proteins, NCS-4, NCS-5, and NCS-7, that share significant sequence similarities to mammalian KChIP3 (Fig. 1A). To determine expression patterns of these putative $C$. elegans KChIP-Like (ceKChIP) genes, we cloned them by ReverseTranscription-PCR and then generated transgenic animals harboring translational GFP reporters. NCS-4 was strongly expressed in body wall and vulva muscles, as well as few neurons in head and tail (Fig. 1B). Translational reporter of NCS-5 was observed in many head neurons and also in body wall muscles in which the GFP signals were relatively weak (Fig. 1C), whereas NCS-7 was only expressed in few neurons in head and tail and some vulva muscles (Fig. 1D). The SHL-1 $\alpha$-subunit (a sole orthology of mammalian Kv4 channel) is widely expressed in posterior intestine, body wall muscles, vulval muscles, male-specific diagonal muscles, and a variety of neurons (Fawcett et al., 2006). This suggests that ceKChIPs may assemble with SHL-1 to form a complex in these tissues.

\section{Each ceKChIP modulates $\mathrm{K}^{+}$Channel SHL-1 in HEK293T cells}

To determine whether NCS-4, NCS-5, and NCS-7 act as regulatory subunits of SHL-1 channel, we coexpressed them with SHL-1 in HEK293T cells to characterize influences of ceKChIPs on SHL-1-elicited currents. The SHL-1 channels, like their mammalian homology Kv4.2, produced a typical fast transient current with fast activation and inactivation (Fig. 2A). Coexpression of ceKChIPs with SHL- 1 altered the characteristics of $\mathrm{K}^{+}$currents. All three ceKChIPs increased peak current densities by $\sim 3$ - to 5 -fold (Fig. $2 A, B$ ) and slowed down inactivation kinetics (Fig. $2 A, C)$. The time course of inactivation at $+80 \mathrm{mV}$ fitted to a single exponential shifted from $\tau=29 \pm 2 \mathrm{~ms}$ for SHL- 1 alone to $256 \pm 20 \mathrm{~ms}$ for the channel formed by SHL-1/NCS-4, $76 \pm 9 \mathrm{~ms}$ for SHL-1/NCS-5, and $156 \pm 13 \mathrm{~ms}$ for SHL-1/NCS-7, respectively (Fig. 2C). Compared with SHL-1 alone (activation $\mathrm{V}_{1 / 2}=$ $20.2 \pm 1 \mathrm{mV}$ ), coexpression of NCS-4 and NCS-5 with SHL-1 shifted the channel activation to more negative potentials with $V_{1 / 2}$ $=10.2 \pm 0.5$ and $14.4 \pm 0.9 \mathrm{mV}$, respectively; coexpression of NCS-7, however, did not affect the activation of SHL-1 channels $\left(V_{1 / 2}=23.5 \pm 0.8 \mathrm{mV}\right.$; Fig. $\left.2 D\right)$. These results suggest that NCS-4, NCS-5, and NCS-7 are regulatory subunits that modulate SHL-1 channels in a manner similar to that of mammalian KChIPs/Kv4.

SHL-1 forms functional complex with ceKChIPs in body wall muscles of C. elegans

We next investigated whether ceKChIPs form functional complexes with SHL-1 in native C. elegans tissues, as translational 
A

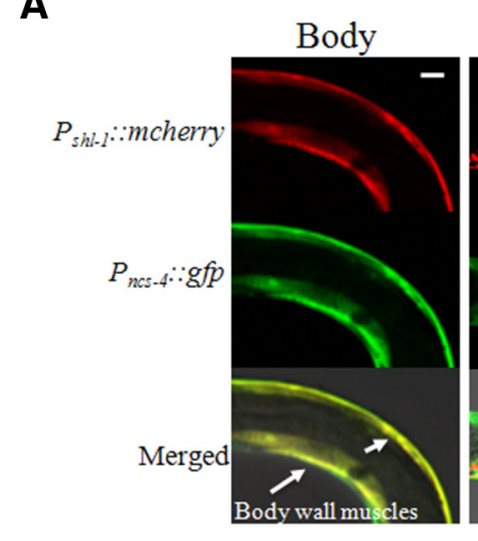

B

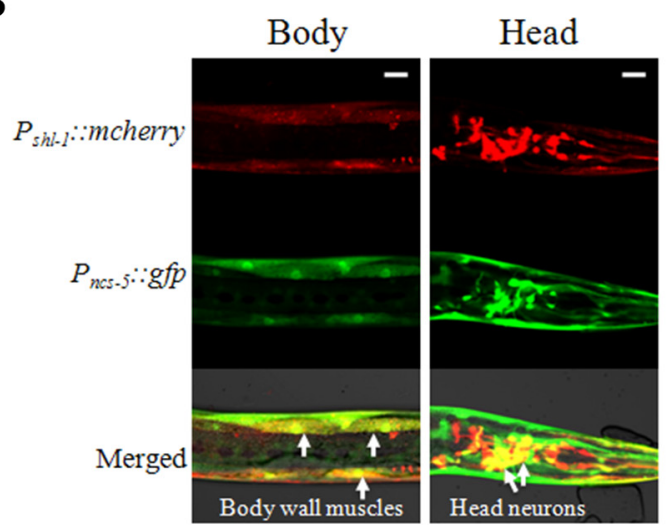

C

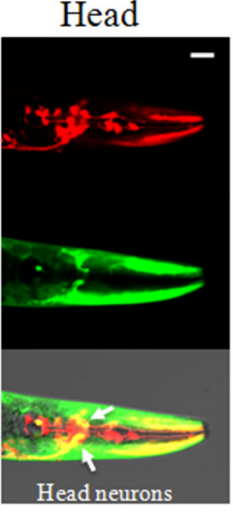

D

$$
\begin{array}{rrrrrrr}
\text { c-Myc-SHL-1 } & - & + & - & + & - & + \\
\text { NCS-4-HA } & + & + & - & - & - & - \\
\text { NCS-5-HA } & - & - & + & + & - & - \\
\text { NCS-7-HA } & - & - & - & - & + & +
\end{array}
$$

IB: Anti-HA

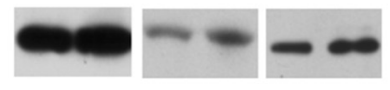

光| Anti-c-Myc
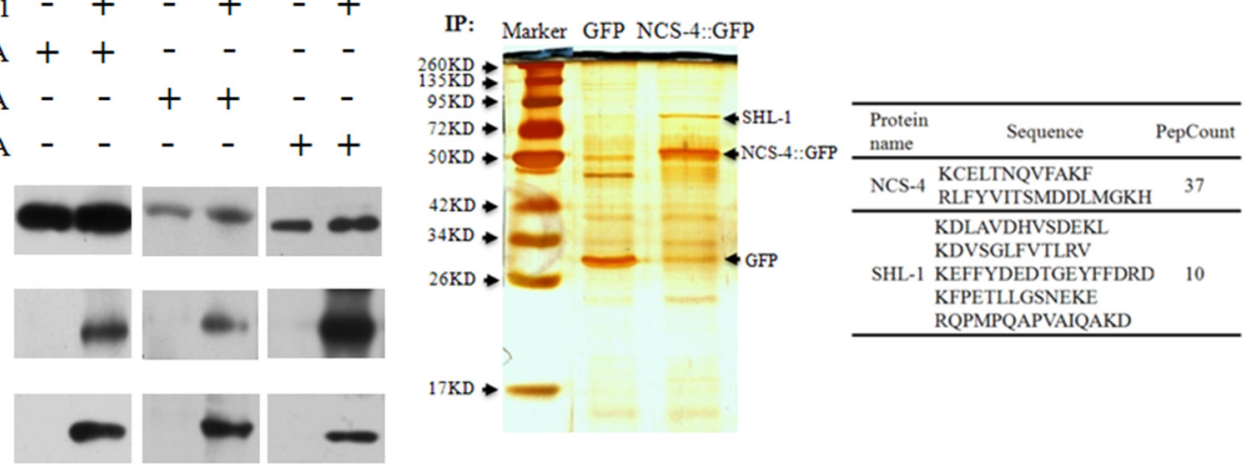

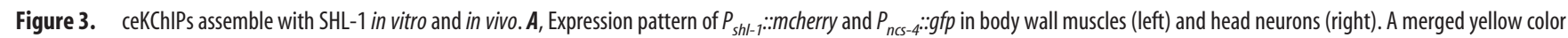

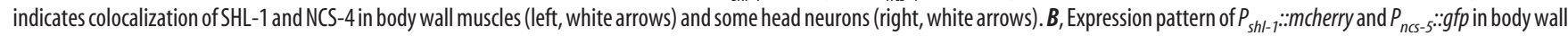
muscles (left) and head neurons (right). A merged yellow color indicates colocalization of SHL-1 and NCS- 5 in body wall muscles (left, white arrows) and some head neurons (right, white arrows). For both $\boldsymbol{A}$ and $\boldsymbol{B}$, scale bars, $20 \mu \mathrm{m}$. C, Coimmunoprecipitation of c-Myc-tagged SHL-1 with HA-tagged NCS-4, NCS-5, and NCS-7 in HEK293T cells. Lysates were immunoprecipitated using c-Myc antibody and protein $\mathrm{A} / \mathrm{G}$ beads. Western visualization was done with anti-c-Myc and anti-HA antibodies. $n=4$ independent experiments. D, SDS-PAGE and silver staining of immunoprecipitates

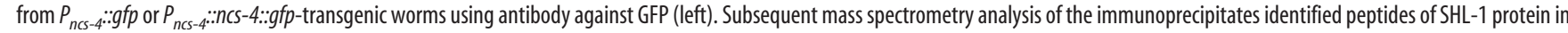
the sample from $P_{n c-4}::$ ncs-4:.:gfp-transgenic worms (right).

reporter analysis and elecrophysiological evidence suggest. Specifically, we detected a strong colocalization of NCS-4 and NCS-5 with SHL-1 in body wall muscles (Fig. $3 A, B$ ). In contrast, only a proportion of head neurons expressed both SHL-1 and its partners NCS-4 and/or NCS-5 (Fig. 3 A, B). All three ceKChIPs coimmunoprecipitated with SHL-1 in HEK293T cell expression system (Fig. 3C).

We then generated transgenic strains expressing GFP or GFP fused NCS-4 (NCS-4::GFP) using the driver of $n c s-4$ promoter. To validate whether NCS-4 and SHL-1 form a complex in vivo, we trapped NCS-4 interacting proteins by pull-down assays using antibody against GFP in extracts prepared from the-transgenic worms. The immunoprecipitates were then resolved by SDSPAGE and proteins were visualized by silver staining. We found several differential bands between extracts prepared fromtransgenic worms expressing GFP and NCS-4::GFP. One of these bands at molecular weight between 70 and $95 \mathrm{kD}$ specifically appeared in the sample from $P_{n c s-4}:: n c s-4:: g f p$-transgenic worms (Fig. 3D). Mass spectrometry analysis subsequently identified several peptides of SHL-1 proteins in this band (Fig. 3D), indicating that SHL-1 and NCS-4 form functional complexes in $C$. elegans.

ceKChIPs are essential components of native SHL-1 channel complexes

The properties of voltage-gated $\mathrm{K}^{+}$currents in body wall muscles of $C$. elegans were first described by Richmond and Jorgensen
(1999). Since then, the components of $\mathrm{K}^{+}$currents in muscle cells have been well documented. Three $\mathrm{K}^{+}$channels, SHK-1, SHL-1, and SLO-2, were reported to constitute the macroscopic outward $\mathrm{K}^{+}$currents in muscle cells (Yuan et al., 2000; Santi et al., 2003; Fawcett et al., 2006; Gao and Zhen, 2011; Liu et al., 2011). Under physiological conditions with low intracellular concentrations of $\mathrm{Cl}^{-}(4-10 \mathrm{mM})$ and $\mathrm{Ca}^{2+}(10-100 \mathrm{nM}), \mathrm{K}^{+}$ currents with typical fast transient outward components were elicited by a series of voltage steps applied from -80 to $+80 \mathrm{mV}$ (in $20 \mathrm{mV}$ increments) from a holding potential of $-80 \mathrm{mV}$ in cultured myocytes of $\mathrm{N} 2$ worms (Fig. $4 A$ ). In contrast, there were no fast transient components in the cultured myocytes from a shl-1-null mutant shl-1(ok1168) (Fig. 4A). This observation is consistent with a previous study (Fawcett et al., 2006) and corroborates the notion that SHL-1 is the only conductor of the fast transient component of the outward $\mathrm{K}^{+}$current in C. elegans muscle cells.

Translational reporter GFP indicated that NCS-4 and NCS-5, but not NCS-7, colocalized in body wall muscles. We then performed whole-cell patch-clamp experiments to determine whether ceKChIPs contribute to forming functional native SHL-1 channels. ncs-4(tm4409) and ncs-5(tm4951), two mutants in which ncs-4 and ncs-5 genes were deleted, respectively, were then used to examine fast transient $\mathrm{K}^{+}$currents in their myocytes. $\mathrm{K}^{+}$currents in cultured myocytes from both ncs4(tm4409) and ncs-5(tm4951) worms displayed a decreased fast 

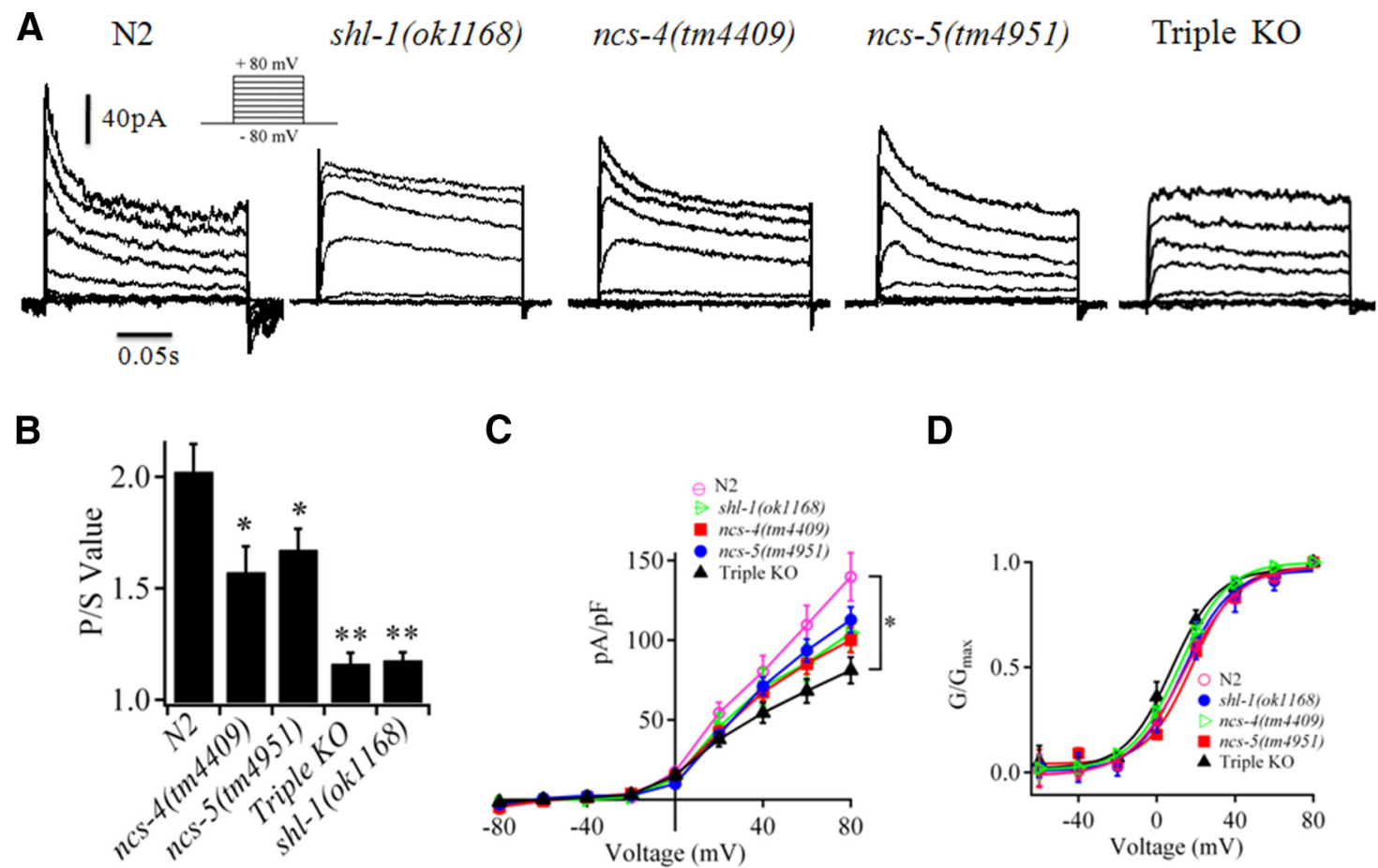

Figure 4. ceKChIPs contribute to generating native SHL- $1 \mathrm{~K}^{+}$current. $A$, Representative whole-cell currents elicited by membrane voltage steps from -80 to $+80 \mathrm{mV}$ with $20 \mathrm{mV}$ increment (inset) in cultured myocytes from N2, shl-1(ok1168), ncs-4(tm4409), ncs-5(tm4951), and ncs-4(tm4409);ncs-7(tm5037);ncs-5(tm4951) (Triple K0) worms. Currents were recorded $4 \mathrm{~d}$ after seeding. $B, P / S$ values of currents at $+80 \mathrm{mV}$ in cultured myocytes of N2, shl-1(ok1168), ncs-4(tm4409), ncs-5(tm4951), and Triple K0 worms. The P/S values were obtained by dividing the peak current by the sustained current at the end of the test pulse. C, Peak current density and voltage $(\sigma-V)$ relationships in cultured myocytes of N2, shl-1(ok1168), ncs-4(tm4409), ncs-5(tm4951), and Triple K0. Data were from $n=12,11,17,15$, and 12 cells, respectively. Mean value of the cultured muscle cell capacitance was 1.2, 1.0, 1.3, 1.1, and 1.1 pF for N2, shl-1(ok1168), ncs-4(tm4409), $n c s-5(t m 4951)$, and Triple K0 worms, respectively. $D, G / G_{\max }$ relationships for N2, shl-1(ok1168), $n c s-4(t m 4409), n c s-5(t m 4951)$, and Triple K0. The theoretical lines were calculated by fitting each curve to the Boltzmann function. $V_{1 / 2}=15.3 \pm 2.4 \mathrm{mV}, K=12.6 \pm 2.2 \mathrm{for} \mathrm{N2}, V_{1 / 2}=13.4 \pm 3.3 \mathrm{mV}, K=12.1 \pm 3.0$ for shl-1(ok1168), $V_{1 / 2}=11.3 \pm 1.9 \mathrm{mV}, K=12.5 \pm 1.7$ for $n c s-4(t m 4409), V_{1 / 2}=18.7 \pm 2.0 \mathrm{mV}, K=11.6 \pm 1.8$ for $n(s-5$ (tm 4951$), V_{1 / 2}=8.0 \pm 2.6 \mathrm{mV}, K=11.9 \pm 2.4$ for Triple K0, respectively. ${ }^{*} p<0.05$, ${ }^{* *} p<0.01$ (unpaired Student's $t$ test). Data shown are mean \pm SEM.

transient component as measured by the $\mathrm{P} / \mathrm{S}$ value obtained by dividing the peak current by the sustained current at the end of the test pulse (Fig. $4 A, B$ ). The $\mathrm{P} / \mathrm{S}$ values at $+80 \mathrm{mV}$ were $1.57 \pm$ 0.10 in $n c s-4$ (tm4409) mutant worms and $1.62 \pm 0.09$ in ncs5(tm4951) mutant worms, respectively, both of which were significantly lower than that in N2 worms $(2.0 \pm 0.1$; each $p<$ $0.05)$, but higher than that in shl-1(ok1168) worms (1.17 \pm 0.03 ; each $p<0.01$ ) (Fig. $4 B$ ). The current density in cultured myocytes of ncs-4(tm4409) or ncs-5(tm4951) worms, however, was not significantly different from that of shl-1(ok1168) worms (Fig. 4C). The results suggest that both NCS-4 and NCS- 5 contribute to native SHL- 1 currents. Furthermore, the fast transient component of outward $\mathrm{K}^{+}$current was not detected in cultured myocytes from the Triple KO mutant worms where all three ceKChIP genes (ncs-4, ncs-5 and ncs-7) were deleted, and accordingly, the P/S value $(1.16 \pm 0.05)$ decreased to the value of shl-1(ok1168) worms (Fig. 4A,B). Peak current density $(\mathrm{pA} / \mathrm{pF})$ at $+80 \mathrm{mV}$ in cultured myocytes from Triple KO mutant was $86 \pm 10$, a value significantly lower than that in $\mathrm{N} 2$ worms $(131 \pm 17, p=0.03)$ (Fig. $4 C)$. The activation of the outward $\mathrm{K}^{+}$currents shifted to more hyperpolarization potential $(8.1 \pm 2.7$ for Triple KO vs $15.3 \pm$ 2.4 for N2 worms) in myocytes of Triple KO mutants, but the value did not change in ncs-4(tm4409) or ncs-5(tm4951) myocytes (Fig. 4D). Together, these results suggest ceKChIPs are indispensable components of SHL- 1 native $\mathrm{K}^{+}$channels.

\section{$\mathrm{Ca}^{2+}$ binding to NCS-4 is required for transporting SHL-1} proteins from the Golgi apparatus to the cell membrane Previous studies have demonstrated that the regulation of $\mathrm{Kv} 4$ channels by KChIPs is $\mathrm{Ca}^{2+}$ dependent to some extent (An et al., 2000; Hasdemir et al., 2005; Pioletti et al., 2006; Anderson et al., 2010), however, the role of $\mathrm{Ca}^{2+}$ signaling in the generation and regulation of native $\mathrm{Kv} 4$ channel is not fully addressed. To answer this question, we constructed a NCS-4 mutant NCS-4(efm) with disrupted $\mathrm{Ca}^{2+}$-binding by mutating highly conserved aspartic acid and glycine residues at positions 1 and 6 , respectively, to alanine within EF-hand motifs 2, 3 and 4 of NCS-4 (Fig. 5A). The mutagenesis sites of NCS-4(efm) are same with that of Triple EF mutant of KChIP1 as described by An et.al (An et al., 2000). In the HEK293T cells, we found that the NCS-4(efm) failed to regulate SHL-1 $\mathrm{K}^{+}$channel currents (Fig. 5B-E), but retained its physical interaction with the channel (Fig. $5 F$ ), consistent with a similar behavior observed in the mammalian orthologs (An et al., 2000).

In parallel experiments, wild-type NCS-4 and EF hand mutated NCS-4(efm) were expressed in the Triple KO worms by $n c s-4$ upstream promoter to explore the role of $\mathrm{Ca}^{2+}$ signaling in maturation of native SHL-1 channels. As expected, reexpression of NCS-4, but not NCS-4(efm) significantly increased the current densities and $\mathrm{P} / \mathrm{S}$ value of outward $\mathrm{K}^{+}$currents (Fig. 6A-C) in cultured myocytes of Triple $\mathrm{KO}$ worms, suggesting $\mathrm{Ca}^{2+}$. binding to EF hands of NCS-4 is essential for the generation of functional SHL-1 channels. A relatively slow inactivation of tran- 
B

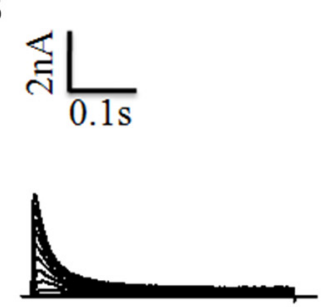

SHL-1

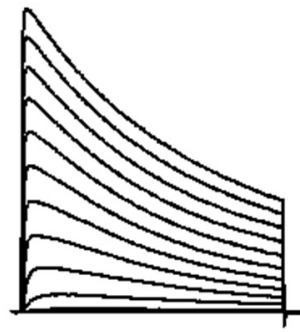

SHL-1+NCS-4
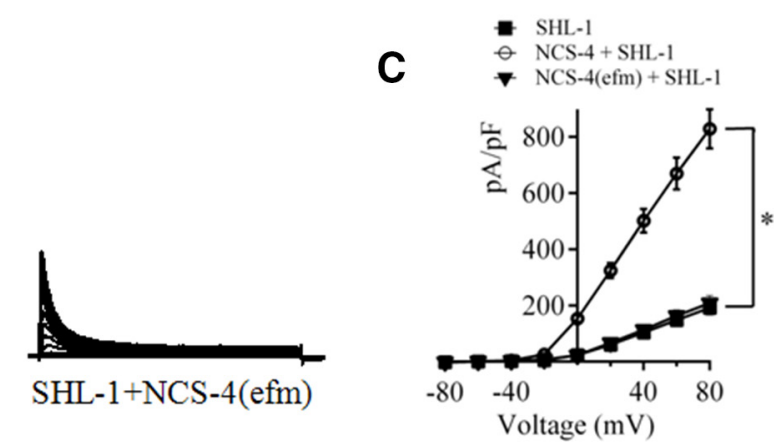

$\mathbf{E}$

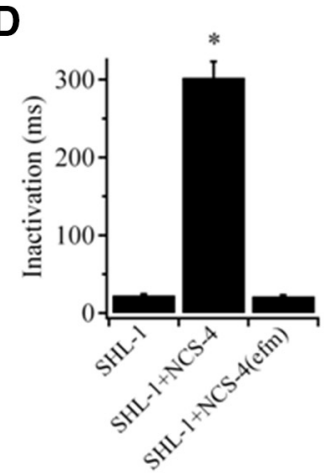

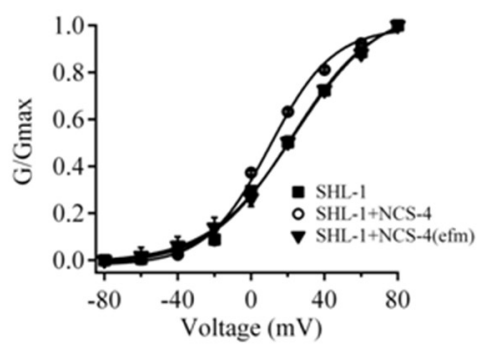

$\mathbf{F}$

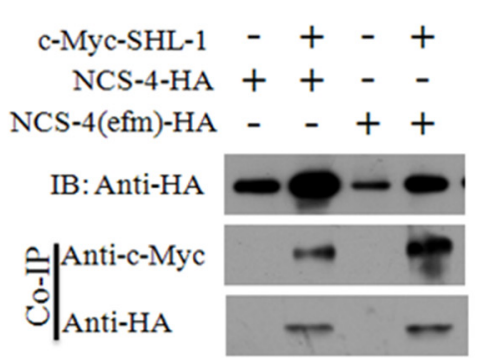

Figure 5. $\mathrm{Ca}^{2+}$-binding ability of NCS-4 is required for regulation of SHL-1 in HEK293T cells. $A, \mathrm{Ca}^{2+}$-binding motif EF hands in NCS-4 protein. In the second, third, and fourth EF hand motifs, first amino acid aspartic acid (D, red) and sixth amino acid glycine (G, red) are well conserved. NCS-4(efm) was generated by mutating both D and $G$ in EF hand motifs to alanine (A). $B$, Representative whole-cell currents recorded from cells expressing SHL-1 alone or with wild-type NCS-4 and EF hand mutant NCS-4(efm), respectively. C, Peak current density-voltage $(\sigma-V)$ relationships for K ${ }^{+}$ channel formed by SHL-1 alone, SHL-1/NCS-4, and SHL-1/NCS-4(efm). Data are from $n=25,23$, and 19 cells, respectively. Peak current densities obtained by dividing peak currents at corresponding voltage by the cell capacitance. Mean value of HEK293T cell capacity was 18.3, 15.5, and 17.8 pF for SHL-1 alone, SHL-1/NCS-4, and SHL-1/NCS-4(efm), respectively. ${ }^{*} p<0.001$ (unpaired Student's $t$ test). D, Inactivation time constants for $\mathrm{K}^{+}$channels formed by SHL-1 alone, SHL-1/NCS-4, and SHL-1/NCS-4(efm) currents at $+80 \mathrm{mV}$. Time constants of inactivation were calculated by fitting macroscopic currents to a single exponential function. ${ }^{*} p<0.001$ (unpaired Student's $t$ test). $E, G / G_{\max }$ relationships for SHL-1 alone, SHL-1/NCS-4, and SHL-1/NCS-4(efm). The theoretical lines were calculated by fitting each curve to the Boltzmann function. For $\boldsymbol{C}-\boldsymbol{E}$, all data shown are mean \pm SEM. $\boldsymbol{F}$, Coimmunoprecipitation of c-Myctagged SHL-1- and HA-tagged NCS-4 and NCS-4(efm). Lysates were immunoprecipitated using $\mathrm{c}-$ Myc antibody and protein $\mathrm{A} / \mathrm{G}$ beads. Western visualization was done with anti-c-Myc and anti-HA antibodies.

sient current was observed in cultured myocytes from

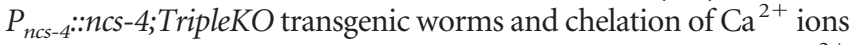
in the pipette solution by addition of $100 \mu \mathrm{M}$ BAPTA, a rapid $\mathrm{Ca}^{2+}$ chelator, speeded up inactivation of the transient current (the Tau value: $64 \pm 5 \mathrm{~ms} v s 35 \pm 7 \mathrm{~ms} ; p<0.05)$ (Fig. $6 D, E$ ) and hence increased the $\mathrm{P} / \mathrm{S}$ value $(1.62 \pm 0.09$ vs $1.88 \pm 0.09 ; p<0.05)$ (Fig. $6 D, E)$. These results suggest that $\mathrm{Ca}^{2+}$ signaling also modulates electrical characteristics of native SHL-1 currents.

Consistent with electrophysiological results that SHL-1 elicited currents were absent in Triple KO mutant myocytes (Fig. $4 A, B$ ), we found that GFP fused SHL-1 (GFP::SHL-1) proteins were expressed in body wall muscles of wild-type N2, but not in that of Triple KO worms (Fig. 7A). GFP::SHL-1 proteins were reexpressed on coexpression with either NCS-4 or NCS-4(efm) driven by $n c s-4$ promoter in body wall muscles of Triple KO worms (Fig. 7A), suggesting that $\mathrm{Ca}^{2+}$ binding ability of NCS-4 are dispensable for the biosynthesis of SHL-1 proteins. Further, we explored whether $\mathrm{Ca}^{2+}$ binding ability of NCS-4 affect trafficking of SHL-1 proteins. Red fluorescence protein mCherry fused mCD8 (Collins and Koelle, 2013), AMAN-2 (an $\alpha$-mannosidase II) (Rolls et al., 2002), signal peptidase SP12 (C34B2.10) (Rolls et al., 2002; Poteryaev et al., 2005), all of which driven by myo-3 promoter, were then used as organelle marker to visualize cell membrane, Golgi apparatus, and endoplasmic reticulum (ER) in body wall muscle cells, respectively. GFP::SHL-1 proteins were enriched at cell membranes of adjacent body wall muscle cells as well as dense body areas, and colocalized with cell membrane marker mCD8 in body wall muscle cells of $\mathrm{N} 2$ and $P_{n c s-4}:$ ncs-4;TripleKO transgenic worms (Fig. $7 B$ ). However, SHL-1 proteins showed no colocalization with mCD8 in body wall muscles of $P_{n c s-4}:: n c s-4(e f m) ; T r i p l e K O$ transgenic worms (Fig. $7 B$ ), suggesting trafficking of the channel was disrupted. Indeed, most of SHL-1 proteins were resided in the Golgi apparatus, as they merged with a Golgi marker AMAN-2, but not an ER marker SP12 in body wall muscles of $P_{n c s-4}: n c s-4$ (efm);TripleKO transgenic worms (Fig. $7 C$ ). Together, the data suggest that $\mathrm{Ca}^{2+}$ binding ability of NCS- 4 is required for trafficking of SHL-1 channels at stage of transporting them from the Golgi apparatus to the cell membrane.

\section{SHL-1/NCS-4 controls turning behavior in male mating}

A slight but significant defect in thrashing behavior and a decreased efficiency in male mating were observed in shl-1(ok1168) worms (Fig. $8 A, B$ ). The result is consistent with previous report (Fawcett et al., 2006). We next investigated how regulation of SHL-1 function by KChIPs affects worm behaviors. In ncs- 
A Triple KO

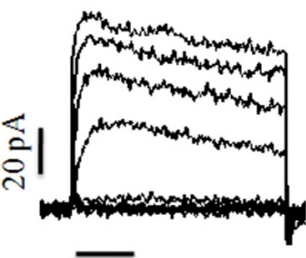
$\overline{0.05 \mathrm{~s}}$
$P_{n c s-4}:: n c s-4$; Triple KO

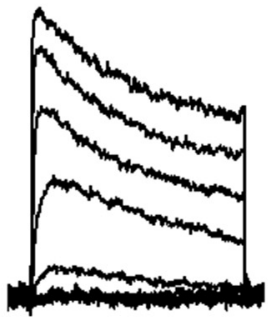

$P_{n c s-4: \because n c s-4(e f m)}$ Triple $\mathrm{KO}$

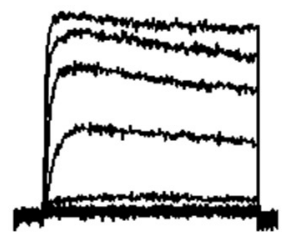

B $\ominus P_{\text {nes-4 }}:$ ncs-4; Triple KO

- Triple KO

$\nabla P_{n c-4}:$ ncs-4(efm); Triple KO

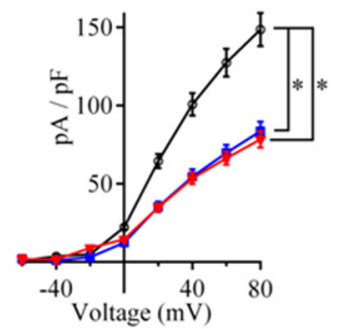

C

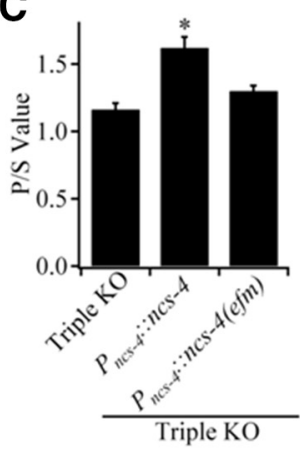

D $P_{n c s-4}: n c s-4 ; \quad P_{n c s-4}:$ ncs-4; Triple Triple KO KO+100 $\mu \mathrm{MBAPTA}$

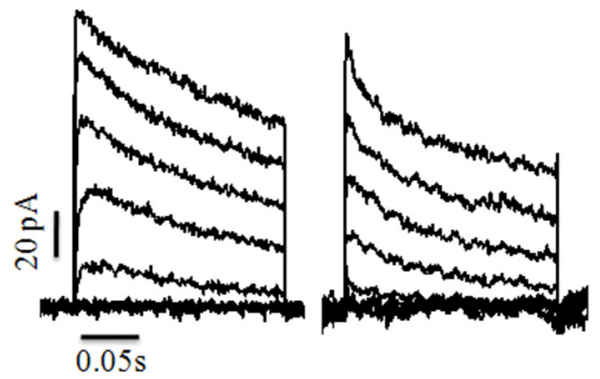

E

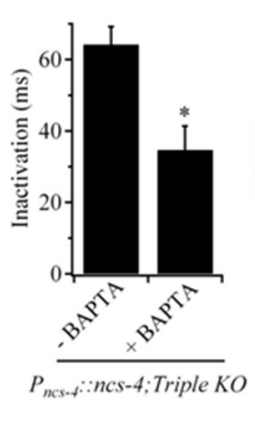

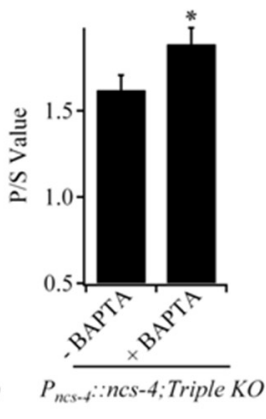

Figure 6. $\mathrm{Ca}^{2+}$ binding to NCS-4 is essential for the generation of functional SHL-1/NCS-4 channels. $A$, Representative whole-cell currents in cultured myocytes from Triple KO,

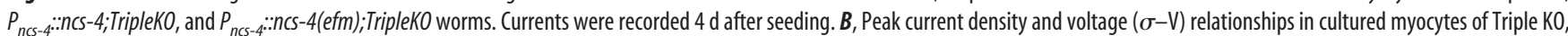

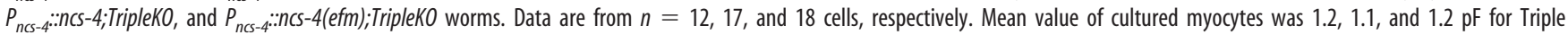

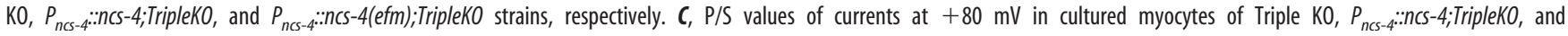

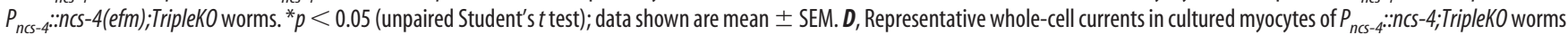
in the absence (left) and presence (right) of $100 \mu \mathrm{m}$ BAPTA. $E$, Inactivation time constants (left) and P/S values (right) of currents in myocytes of $P_{n c s-4}:$ :ncs-4; Triple K0 with or without $100 \mu \mathrm{m} \mathrm{BAPTA}$ in pipette solution at $+80 \mathrm{mV}$. Data are from $>10$ cells per treatment. Time constants were calculated by fitting macroscopic currents to a single exponential function. ${ }^{*} p<0.05$ (unpaired Student's $t$ test). Data shown are mean \pm SEM.

4(tm4409), ncs-5(tm4951), and Triple KO worms, the speed of thrashing in M9 solution decreased to a level comparable to that in shl-1(ok1168) mutants (Fig. 8A). In contrast, the ability to mate with hermaphrodites was quite different among ceKChIP mutant males (Fig. 8B). The mating efficiency of ncs-4(tm4409) and Triple KO mutant males decreased to a level similar to that of shl-1(ok1168) males, whereas that of ncs-5(tm4951) males was not statistically different from that of wild-type N2 worms (Fig. $8 B$ ). Double deletion of $n c s-4$ and $s h l-1$ genes did not further reduce the male mating efficiency (Fig. $8 B$ ), suggesting that NCS-4 modulates male mating behaviors through regulating the function of SHL-1 channels.

Male mating is among most complex behaviors in C. elegans. It involves a series of steps including, response, backing, turning, vulva location, spicule insertion, and sperm transfer (Emmons and Sternberg, 1997; Barr and Garcia, 2006). To determine which $\operatorname{step}(\mathrm{s})$ of mating behaviors is impaired by the absence of SHL-1/ NCS $-4 \mathrm{~K}^{+}$channels, we recorded male mating processes. We found that $75 \%$ of shl-1 (ok1168) males and 70\% of ncs-4(tm4409) males failed to complete a turning behavior when they tried to mate. In contrast, only $10 \%$ of $\mathrm{N} 2$ males and $23 \%$ of ncs5(tm4951) males displayed unsuccessful turning during an attempt to mate (Fig. 8C).

Turning behaviors are controlled by male-specific diagonal muscles (Emmons and Sternberg, 1997; Barr and Garcia, 2006), in which expression of SHL-1 has been observed previously
(Fawcett et al., 2006). Translational reporter GFP showed that NCS-4, but not NCS-5, was expressed in male specific diagonal muscle (Fig. 8C). NCS-4 thus may assemble with SHL-1 to form native SHL-1/NCS-4 channel complexes that regulate the excitability of diagonal muscles. We then monitored diagonal muscle activity during male turning of mating behavior with ratiometric $\mathrm{Ca}^{2+}$ imaging by expressing the $\mathrm{Ca}^{2+}$ indicator protein $\mathrm{G}$ CaMP5 in the muscles together with DsRed2 (both via unc-68 promoter). To minimize movement during $\mathrm{Ca}^{2+}$ imaging, paralyzed unc-54(e190) hermaphrodites were used to mate with N2, shl-1(ok1168), and ncs-4(tm4409) males. We found that the $\mathrm{Ca}^{2+}$ signals in the diagonal muscles of $\mathrm{N} 2$ males began to increase when their posterior tails approached the end of hermaphrodites (head or tail) during the backing step and reached the maximum when males attempted to turning their tails. After turning, the $\mathrm{Ca}^{2+}$ signals decreased quickly (Fig. 8D). In contrast, both shl-1(ok1168) and ncs-4(tm4409) males showed a sustained higher level of $\mathrm{Ca}^{2+}$ signals, as reflected by fact that the values of $\Delta R / R_{0}$ in diagonal muscles of these mutant males were significant higher than those in N2 males at time points of $-0.5,0,0.5$, and $1 \mathrm{~s}$ (Fig. 8D). These results suggest that both mutant males had a defect in regulating excitability of their diagonal muscles. Thus, ceKChIPs play an important role in controlling locomotion and male mating behaviors by regulating the function of SHL-1 $\mathrm{K}^{+}$channels in C. elegans.

We then investigated whether disruption of a link between $\mathrm{Ca}^{2+}$ signaling and SHL-1/NCS-4 has an adverse effect on male 

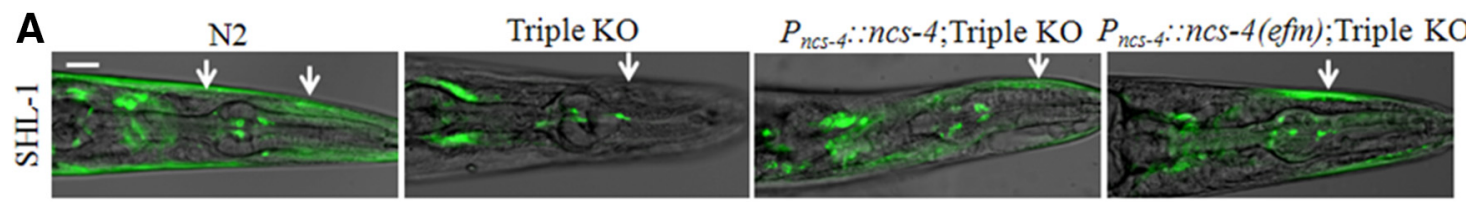

B

N2
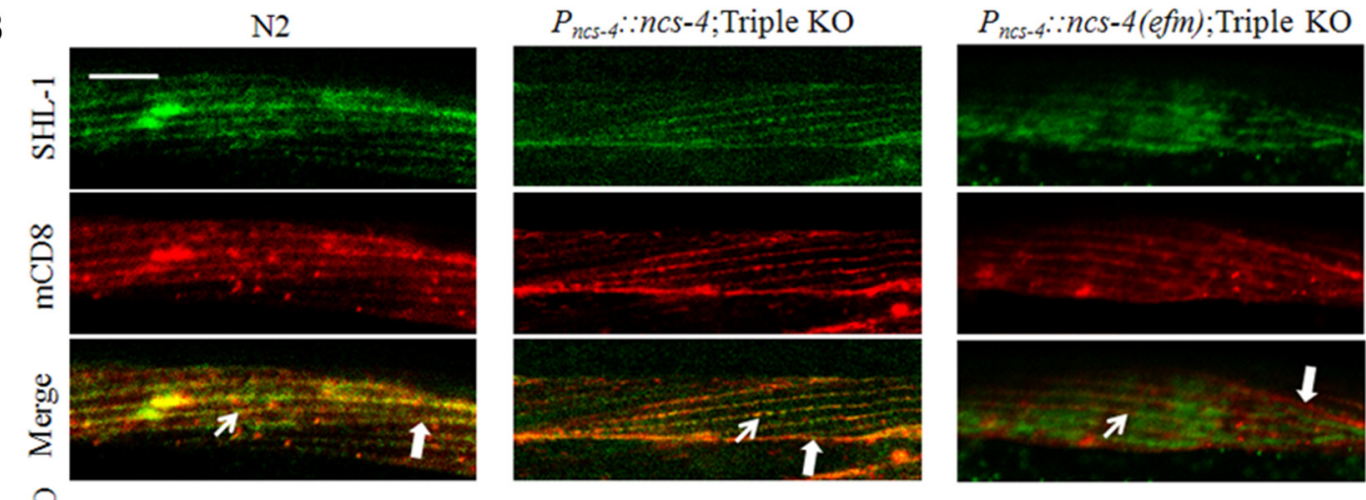

C
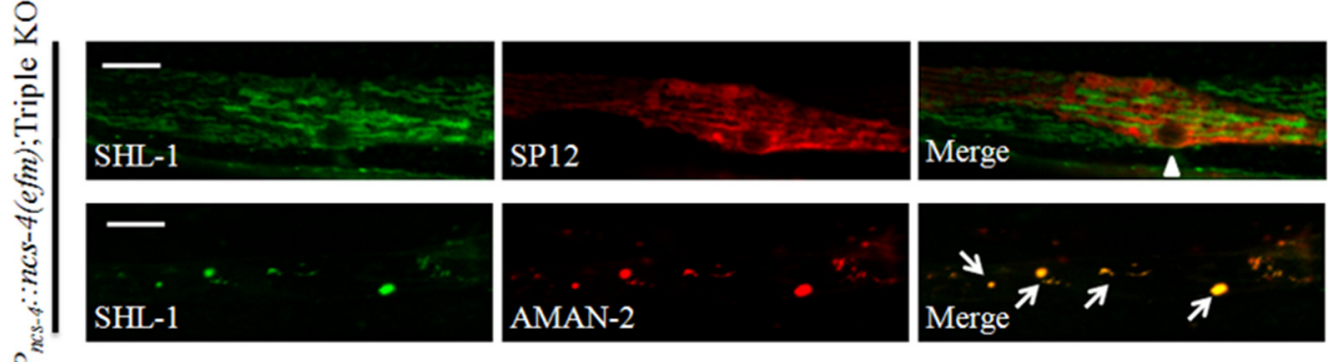

Figure 7. $\mathrm{Ca}^{2+}$ binding to NCS-4 is required for trafficking SHL-1 channels from the Golgi apparatus to the cell membrane. $A$, Expression pattern of SHL-1 proteins in body wall muscles of N2, Triple K0, $P_{\text {ncs-4 }}:$ NCS-4; TripleKO, and $P_{n c-4}:: n c s-4(e f m) ;$ TripleKO worms. SHL-1 was fused with GFP at N terminus. Scale bar, $20 \mu \mathrm{m}$. White arrows indicate head muscles. B, Distribution of SHL-1

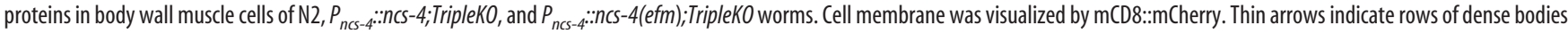

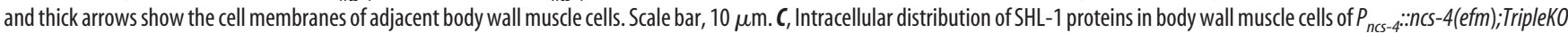
worms. The organelles endoplasmic reticulum (top) and Golgi apparatus (bottom) of the cells were visualized by SP12::mCherry and AMAN-2::mCherry, respectively. Triangle and arrows indicate nucleus of body wall muscle cells and Golgi vesicles, respectively. Scale bar, $10 \mu \mathrm{m}$. In all cases, $>10$ worms per genotype were examined.

mating behaviors of C. elegans. Indeed, we found that reintroduction of wild-type NCS-4, but not the NCS-4(efm), fully rescued the defects in turning behaviors and thus mating efficiency of $n c s-4$ (tm4409) males (Fig. 8E). The result is consistent with the finding that disruption of $\mathrm{Ca}^{2+}$-binding ability of NCS-4 disturbed the trafficking of SHL-1 proteins in body wall muscles. Therefore, $\mathrm{Ca}^{2+}$-dependent regulation is necessary for SHL-1/ ceKChIPs channels to control worm behavior.

\section{Discussion}

ceKChIPs are essential components of SHL-1 channel complexes in C. elegans

In this study, we provide molecular evidence that ceKChIPs are essential components of the native SHL-1 channel complex in $C$. elegans muscle cells. This was supported by at least three lines of evidence. First, ceKChIPs NCS-4, NCS-5, and NCS-7 modified kinetic characteristics of SHL-1 currents in vivo and in vitro. Second, NCS-4 and NCS-5 colocalized and physically interacted with SHL-1 in heterologous expressing systems and in the native tissues. Finally, deletion of ncs-4 or ncs-5 gene significantly reduced the fast transient component of outward $\mathrm{K}^{+}$currents in myocytes and, more importantly, abolishment of all ceKChIPs identified in this study totally eliminated the SHL-1 elicited outward currents in C. elegans muscle cells. Our data also supported the hypothesis that the function of SHL-1 is dependent on the expression of ceKChIPs. Similar codependence of Kv4 and KChIPs has been observed in mammalian neurons and cardiac cells (Kuo et al., 2001; Norris et al., 2010), suggesting a conserved mechanism underlying the interaction between Kv4 channels and KChIPs across species. Likewise, the interdependent role of $\operatorname{Kv} \alpha$ and accessory subunits also has been observed in other subfamilies of Kv channels (Bianchi et al., 2003; Wu et al., 2010). This may represent a fundamental principle for linking the biogenesis of $\mathrm{K}^{+}$channel accessory and pore-forming subunits.

Our study also reveals a novel mechanism underlying modulation of Kv4 by KChIPs in vivo. Previous studies in heterogeneous expressing systems have demonstrated that KChIPs promote the intracellular trafficking of $\mathrm{Kv} 4$ by releasing the channel from intrinsic endoplasmic reticulum retention (Shibata et al., 2003). The regulation is profoundly affected by $\mathrm{Ca}^{2+}$ signaling, and the $\mathrm{Ca}^{2+}$ binding ability of KChIPs is required for Kv4.2 channels reaching the Golgi complexes (An et al., 2000; Hasdemir et al., 2005). Obviously, KChIPs have a more versatile role in maturation of $\mathrm{Kv} 4$ channel complexes in vivo because they also facilitate the biogenesis of $\mathrm{Kv} 4$ channels by stabilizing nascent proteins. The $\mathrm{Ca}^{2+}$ binding ability to EF hands is dispensable for KChIPs facilitating the biogenesis of $\mathrm{Kv} 4$ channels in vivo, in disagreement with the observation that disruption of $\mathrm{Ca}^{2+}$ binding abolished modulation of Kv4.2 by KChIPs in cultured cells (An et al., 2000; Pioletti et al., 2006). In addition, $\mathrm{Ca}^{2+}$ binding to KChIPs is required at stage of transporting $\mathrm{Kv} 4$ from the Golgi complex to the cell membrane in vivo (Fig. $7 B, C$ ) rather than from the ER to the Golgi apparatus as found in cultured cells 
A

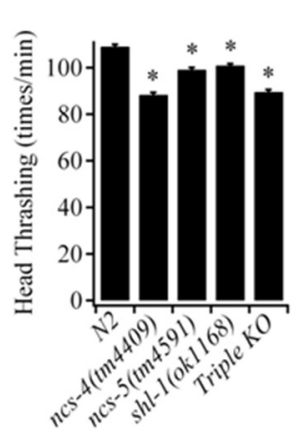

B

D

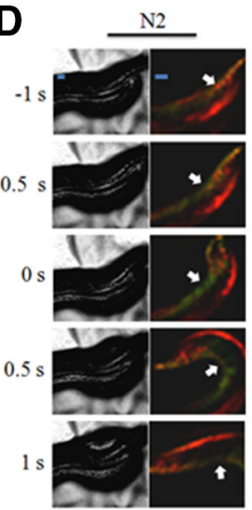

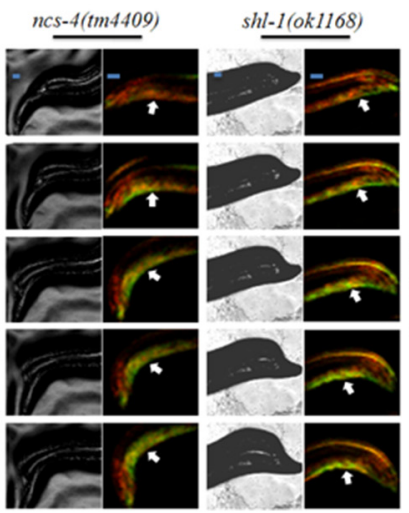

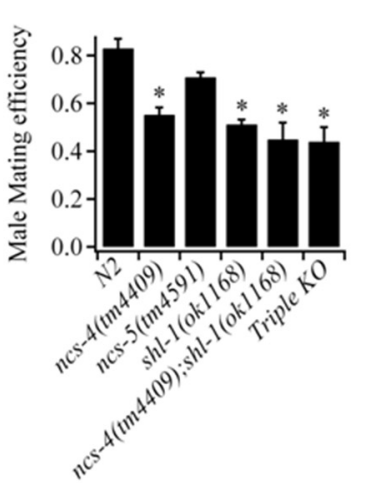

C

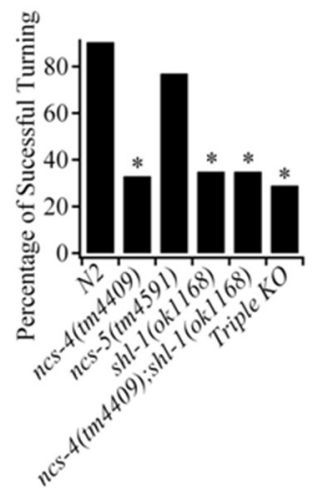

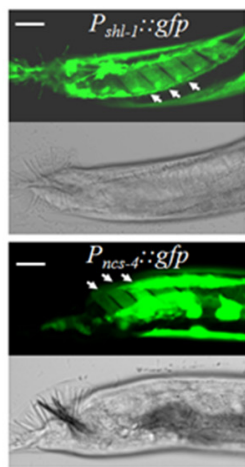

E
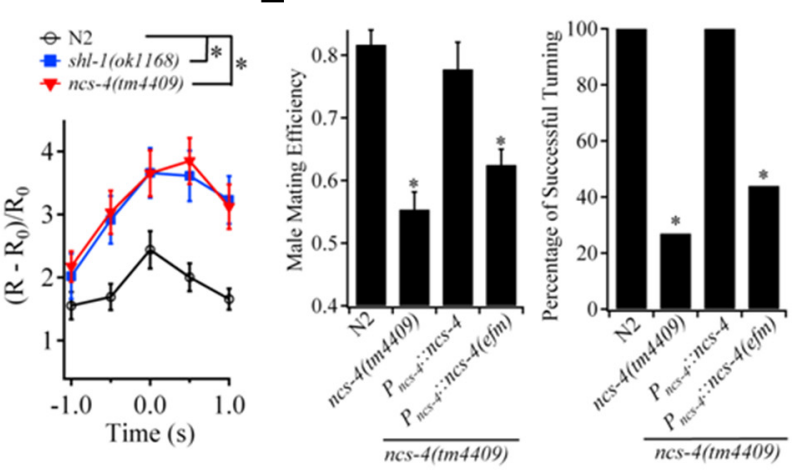

Figure 8. NCS-4 modulates turning behavior in male mating in C. elegans. $\boldsymbol{A}$, Head thrashing of N2, ncs-4(tm4409), ncs-5(tm4951), Triple K0, and shl-1(ok1168) worms. Data are from at least three independent experiments ( $\geq 20$ worms per genotype per experiment). ${ }^{*} p<0.05$ (unpaired Student's $t$ test). B, Mating efficiency of N2, ncs-4(tm4409), $n c s-5$ (tm4951), Triple K0, shl-1(ok1168), and ncs-4(tm4409); shl-1(ok1168) males. Data were from at least three independent experiments; $n \geq 20$ males per genotype per experiment. ${ }^{*} p<0.05$ (unpaired Student's $t$ test). C, Left, turning behavior of male mating in N2, ncs-4(tm4409), ncs-5(tm4951), Triple K0, shl-1(ok1168), and ncs-4(tm4409); shl-1(ok1168) males. More than 20 males per genotype were recorded in a total of three independent experiments. ${ }^{*} p<0.05$ (Fisher's exact test). Right, Fluorescent confocal microscopy and phase-contrast light images of diagonal muscles in $P_{\text {shl- }-: .9 f p \text {-transgenic }}$

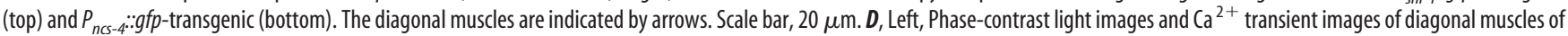
N2, ncs-4(tm4409), and shl-1(ok1168) male worms during turning behavior in mating. Individual tested male mated with paralyzed unc-54(e190) hermaphrodites. The time point that the tested male started to flex its tail is defined as time 0 . The green and red indicate the fluorescence of GCaMP5 and DsRed2, respectively. Arrows indicate diagonal muscles. Scale bar, $20 \mu \mathrm{m}$. Right, Changes in $\Delta R / R_{0}$ at diagonal muscles of N2, ncs-4(tm4409), and shl-1(ok1168) males during turning behavior. $R$ represents the ratio of GCaMP5/DsRed2 fluorescence. The value of GCaMP5/DsRed2 in diagonal muscles of the same male moving alone (without hermaphrodite) was regarded as $R_{0}$. Data were obtained from $>15$ males per genotype in a total of four independent experiments. ${ }^{*} \Delta R / R_{0}$ in diagonal muscles of $n c s-4(t m 4409)$ and shl-1(ok1168) males are significant higher than that in N2 males at time points of $-0.5,0,0.5$, and $1 \mathrm{~s},{ }^{*} p<0.05$ (unpaired Student's $t$ test). $\boldsymbol{E}$, Left, mating efficiency of N2, ncs-4(tm4409), $P_{n c s-4}:: n c s-4 ; n c s-4\left(\right.$ tm4409), and $P_{n c s-4}:: n c s-4($ efm); $n c s-4(t m 4409)$ males. Data are from at least three independent experiments, $n \geq 20$ males per

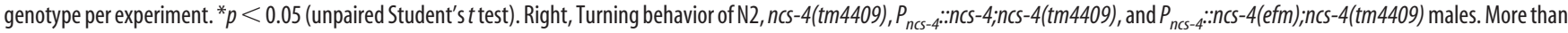
20 males per genotype were recorded in a total of three independent experiments. ${ }^{*} p<0.05$ (Fisher's exact test). In all cases, data shown are mean \pm SEM.

(Hasdemir et al., 2005). The discrepancy may simply come from the different experimental systems. Our findings thus provide new insights into how KChIPs modulate Kv4 channels in vivo.

\section{Three ceKChIPs modulate cell excitability}

ceKChIPs, like SHL-1, are involved in the control of body wall muscle cell excitability. They not only promote the biogenesis of SHL- $1 \mathrm{~K}^{+}$current, but also modulate the current characteristics in muscle cells. Previous studies have demonstrated that the SHL-1 native channels activate in a more hyperpolarized voltage ( $\sim 14 \mathrm{mV}$ shift) than the cloned channels expressed in heterologous systems (Santi et al., 2003; Fawcett et al., 2006; Wu et al., 2010). Our data reveal that the discrepancy could be due to the existence of ceKChIPs. Coexpression of NCS-4 or NCS-5 with SHL-1 significantly shifted the voltage dependence of activation to $\sim 13$ or $10 \mathrm{mV}$ more hyperpolarized voltage, respectively. The channel complex formed by SHL-1 and NCS-4 or NCS-5 was activated at the $V_{1 / 2} \sim 10 \mathrm{mV}$, similar to that of the native SHL-1 channel. This finding also further supports the hypothesis that SHL-1 and NCS-4/NCS-5 assemble together to generate native fast transient outward currents in C. elegans muscle cells. We also noted that the time course of SHL-1/NCS-4 or SHL-1/NCS-5 currents inactivation in a heterogolous system is slower than that of native SHL-1-elicited currents. The difference could be due to many possible factors, including possible additional ancillary subunits (e.g., DPPLs), stoichiometry of NCS-4/NCS-5 and SHL-1, as well as posttranslational modification occurring in native cells.

A pore-forming $\alpha$ subunit of the $\mathrm{Kv} 4$ channel could assemble with multiple accessory subunits. Therefore, the stoichiometry of the KChIPs and $\mathrm{Kv} 4$ determines the molecular diversity of native channels that are critical for fine-tuning cell excitability in different tissues. Our data show that SHL-1 channel could assemble with NCS-4 and NCS-5 in body wall muscles. It is very likely that SHL-1 simultaneously binds to NCS-4 and NCS-5, but we could not rule out the possibility that it assembles individually with these KChIPs in a certain muscle cell. Interestingly, SHL-1 only assembles with a single type of KChIP, NCS-4, in male-specific diagonal muscles. All three ceKChIPs are expressed in the nervous system of $C$. elegans and colocalize with SHL-1 in some 
neurons. This indicates that ceKChIPs may also modulate neuronal excitability, but their physiological roles remain to be determined. The expression of ceKChIPs and SHL-1 is not completely overlapped in the nervous system, so other ancillary components of SHL-1 may exist in neurons of C. elegans.

\section{SHL-1/NCS-4 control turning behavior in male mating}

Male mating is the most complex behavior exhibited by the nematode C. elegans and involves the steps of response, backing, turning, vulva location, spicule insertion, and sperm transfer (Emmons and Sternberg, 1997; Barr and Garcia, 2006). The excitability of neurons and muscles need to be fine-tuned for the optimal performance of the complex behavior. An interaction between BK and EAG family $\mathrm{K}^{+}$channels produces the muscle excitability levels that regulate the timing of spicule protraction during male mating (LeBoeuf and Garcia, 2012). Here, we show that SHL-1/NCS-4 channel complexes regulate the excitability of male diagonal muscles and control turning behavior in male mating. Previously, the defect in mating behaviors of shl-1(ok1168) males has been shown to result in the inability to locate the vulva (Fawcett et al., 2006). We also observed a defect in the vulva location in a limited number of shl-1(ok1168) mutant males who turned successfully (data not shown). However, given that turning occurs before vulva location during mating, the impairment of mating behaviors in $n c s-4(t m 4409)$ and shl-1(ok1168) males may be primarily due to a defect in the turning process. Conceivably, removal of SHL-1 channels by deletion of either the ncs- 4 or shl-1 gene results in hypersensitivity of the diagonal muscle to Ach and then stiffening of the diagonal muscle during the turning step of male mating.

\section{References}

Abbott GW, Sesti F, Splawski I, Buck ME, Lehmann MH, Timothy KW, Keating MT, Goldstein SA (1999) MiRP1 forms IKr potassium channels with HERG and is associated with cardiac arrhythmia. Cell 97:175-187. CrossRef Medline

Abbott GW, Butler MH, Bendahhou S, Dalakas MC, Ptacek LJ, Goldstein SA (2001) MiRP2 forms potassium channels in skeletal muscle with Kv3.4 and is associated with periodic paralysis. Cell 104:217-231. CrossRef Medline

Akerboom J, Chen TW, Wardill TJ, Tian L, Marvin JS, Mutlu S, Calderón NC, Esposti F, Borghuis BG, Sun XR, Gordus A, Orger MB, Portugues R, Engert F, Macklin JJ, Filosa A, Aggarwal A, Kerr RA, Takagi R, Kracun S, et al. (2012) Optimization of a GCaMP calcium indicator for neural activity imaging. J Neurosci 32:13819-13840. CrossRef Medline

An WF, Bowlby MR, Betty M, Cao J, Ling HP, Mendoza G, Hinson JW, Mattsson KI, Strassle BW, Trimmer JS, Rhodes KJ (2000) Modulation of A-type potassium channels by a family of calcium sensors. Nature 403: 553-556. CrossRef Medline

Anderson D, Mehaffey WH, Iftinca M, Rehak R, Engbers JD, Hameed S, Zamponi GW, Turner RW (2010) Regulation of neuronal activity by Cav3-Kv4 channel signaling complexes. Nat Neurosci 13:333-337. CrossRef Medline

Barr MM, Garcia LR (2006) Male mating behavior. WormBook:1-11.

Bianchi L, Kwok SM, Driscoll M, Sesti F (2003) A potassium channel-MiRP complex controls neurosensory function in Caenorhabditis elegans. J Biol Chem 278:12415-12424. CrossRef Medline

Birnbaum SG, Varga AW, Yuan LL, Anderson AE, Sweatt JD, Schrader LA (2004) Structure and function of Kv4-family transient potassium channels. Physiol Rev 84:803-833. CrossRef Medline

Brenner R, Chen QH, Vilaythong A, Toney GM, Noebels JL, Aldrich RW (2005) BK channel beta4 subunit reduces dentate gyrus excitability and protects against temporal lobe seizures. Nat Neurosci 8:1752-1759. CrossRef Medline

Cai SQ, Sesti F (2009) Oxidation of a potassium channel causes progressive sensory function loss during aging. Nat Neurosci 12:611-617. CrossRef Medline

Cai SQ, Hernandez L, Wang Y, Park KH, Sesti F (2005) MPS-1 is a K+ channel beta-subunit and a serine/threonine kinase. Nat Neurosci 8:1503-1509. CrossRef Medline

Cai SQ, Li W, Sesti F (2007) Multiple modes of a-type potassium current regulation. Curr Pharm Des 13:3178-3184. CrossRef Medline

Cai SQ, Wang Y, Park KH, Tong X, Pan Z, Sesti F (2009) Autophosphorylation of a voltage-gated $\mathrm{K}+$ channel controls non-associative learning. EMBO J 28:1601-1611. CrossRef Medline

Christensen M, Estevez A, Yin X, Fox R, Morrison R, McDonnell M, Gleason C, Miller DM 3rd, Strange K (2002) A primary culture system for functional analysis of C. elegans neurons and muscle cells. Neuron 33:503-514. CrossRef Medline

Collins KM, Koelle MR (2013) Postsynaptic ERG potassium channels limit muscle excitability to allow distinct egg-laying behavior states in Caenorhabditis elegans. J Neurosci 33:761-775. CrossRef Medline

Davis MW, Fleischhauer R, Dent JA, Joho RH, Avery L (1999) A mutation in the C. elegans EXP-2 potassium channel that alters feeding behavior. Science 286:2501-2504. CrossRef Medline

Elkes DA, Cardozo DL, Madison J, Kaplan JM (1997) EGL-36 Shaw channels regulate C. elegans egg-laying muscle activity. Neuron 19:165-174. CrossRef Medline

Emmons SW, Sternberg PW (1997) Male development and mating behavior. In: Riddle DL, Blumenthal T, Meyer BJ, Priess JR (eds). C. elegans II, Ed 2. Cold Spring Harbor, NY: Cold Spring Harbor Laboratory; pp 295-334.

Fawcett GL, Santi CM, Butler A, Harris T, Covarrubias M, Salkoff L (2006) Mutant analysis of the Shal (Kv4) voltage-gated fast transient $\mathrm{K}+$ channel in Caenorhabditis elegans. J Biol Chem 281:30725-30735. CrossRef Medline

Gao S, Zhen M (2011) Action potentials drive body wall muscle contractions in Caenorhabditis elegans. Proc Natl Acad Sci U S A 108:2557-2562. CrossRef Medline

Garcia LR, Sternberg PW (2003) Caenorhabditis elegans UNC-103 ERG-like potassium channel regulates contractile behaviors of sex muscles in males before and during mating. J Neurosci 23:2696-2705. Medline

Hasdemir B, Fitzgerald DJ, Prior IA, Tepikin AV, Burgoyne RD (2005) Traffic of $\mathrm{Kv} 4 \mathrm{~K}+$ channels mediated by KChIP1 is via a novel post-ER vesicular pathway. J Cell Biol 171:459-469. CrossRef Medline

Holmqvist MH, Cao J, Knoppers MH, Jurman ME, Distefano PS, Rhodes KJ, Xie Y, An WF (2001) Kinetic modulation of Kv4-mediated A-current by arachidonic acid is dependent on potassium channel interacting proteins. J Neurosci 21:4154-4161. Medline

Jerng HH, Kunjilwar K, Pfaffinger PJ (2005) Multiprotein assembly of Kv4.2, KChIP3 and DPP10 produces ternary channel complexes with ISA-like properties. J Physiol 568:767-788. CrossRef Medline

Johnstone DB, Wei A, Butler A, Salkoff L, Thomas JH (1997) Behavioral defects in C. elegans egl-36 mutants result from potassium channels shifted in voltage-dependence of activation. Neuron 19:151-164. CrossRef Medline

Kage-Nakadai E, Kobuna H, Funatsu O, Otori M, Gengyo-Ando K, Yoshina S, Hori S, Mitani S (2012) Single/low-copy integration of transgenes in Caenorhabditis elegans using an ultraviolet trimethylpsoralen method. BMC Biotechnol 12:1. CrossRef Medline

Kuo HC, Cheng CF, Clark RB, Lin JJ, Lin JL, Hoshijima M, Nguyễn-Trân VT, Gu Y, Ikeda Y, Chu PH, Ross J, Giles WR, Chien KR (2001) A defect in the Kv channel-interacting protein 2 (KChIP2) gene leads to a complete loss of I(to) and confers susceptibility to ventricular tachycardia. Cell 107:801-813. CrossRef Medline

LeBoeuf B, Garcia LR (2012) Cell excitability necessary for male mating behavior in Caenorhabditis elegans is coordinated by interactions between big current and ether-a-go-go family K $(+)$ channels. Genetics 190:10251041. CrossRef Medline

Li Y, Um SY, McDonald TV (2006) Voltage-gated potassium channels: regulation by accessory subunits. Neuroscientist 12:199-210. CrossRef Medline

Liu P, Ge Q, Chen B, Salkoff L, Kotlikoff MI, Wang ZW (2011) Genetic dissection of ion currents underlying all-or-none action potentials in $C$. elegans body-wall muscle cells. J Physiol 589:101-117. CrossRef Medline

Maryon EB, Saari B, Anderson P (1998) Muscle-specific functions of ryanodine receptor channels in Caenorhabditis elegans. J Cell Sci 111:28852895. Medline

Norris AJ, Foeger NC, Nerbonne JM (2010) Interdependent roles for accessory KChIP2, KChIP3, and KChIP4 subunits in the generation of Kv4-encoded IA channels in cortical pyramidal neurons. J Neurosci 30:13644-13655. CrossRef Medline 
Park KH, Hernandez L, Cai SQ, Wang Y, Sesti F (2005) A family of K+ channel ancillary subunits regulate taste sensitivity in Caenorhabditis elegans. J Biol Chem 280:21893-21899. CrossRef Medline

Patel SP, Campbell DL, Strauss HC (2002) Elucidating KChIP effects on Kv4.3 inactivation and recovery kinetics with a minimal KChIP2 isoform. J Physiol 545:5-11. CrossRef Medline

Pioletti M, Findeisen F, Hura GL, Minor DL Jr (2006) Three-dimensional structure of the KChIP1-Kv4.3 T1 complex reveals a cross-shaped octamer. Nat Struct Mol Biol 13:987-995. CrossRef Medline

Pongs O, Schwarz JR (2010) Ancillary subunits associated with voltagedependent K+ channels. Physiol Rev 90:755-796. CrossRef Medline

Poteryaev D, Squirrell JM, Campbell JM, White JG, Spang A (2005) Involvement of the actin cytoskeleton and homotypic membrane fusion in ER dynamics in Caenorhabditis elegans. Mol Biol Cell 16:2139-2153. CrossRef Medline

Rhodes KJ, Carroll KI, Sung MA, Doliveira LC, Monaghan MM, Burke SL, Strassle BW, Buchwalder L, Menegola M, Cao J, An WF, Trimmer JS (2004) KChIPs and Kv4 alpha subunits as integral components of A-type potassium channels in mammalian brain. J Neurosci 24:7903-7915. CrossRef Medline

Richmond JE, Jorgensen EM (1999) One GABA and two acetylcholine receptors function at the C. elegans neuromuscular junction. Nat Neurosci 2:791-797. CrossRef Medline

Roepke TK, King EC, Reyna-Neyra A, Paroder M, Purtell K, Koba W, Fine E, Lerner DJ, Carrasco N, Abbott GW (2009) Kcne2 deletion uncovers its crucial role in thyroid hormone biosynthesis. Nat Med 15:1186-1194. CrossRef Medline

Rolls MM, Hall DH, Victor M, Stelzer EH, Rapoport TA (2002) Targeting of rough endoplasmic reticulum membrane proteins and ribosomes in invertebrate neurons. Mol Biol Cell 13:1778-1791. CrossRef Medline

Santi CM, Yuan A, Fawcett G, Wang ZW, Butler A, Nonet ML, Wei A, Rojas P, Salkoff L (2003) Dissection of K+ currents in Caenorhabditis elegans muscle cells by genetics and RNA interference. Proc Natl Acad Sci U S A 100:14391-14396. CrossRef Medline

Schulte U, Thumfart JO, Klöcker N, Sailer CA, Bildl W, Biniossek M, Dehn D, Deller T, Eble S, Abbass K, Wangler T, Knaus HG, Fakler B (2006) The epilepsy-linked Lgil protein assembles into presynaptic Kvl channels and inhibits inactivation by Kvbeta1. Neuron 49:697-706. CrossRef Medline
Sesti F, Abbott GW, Wei J, Murray KT, Saksena S, Schwartz PJ, Priori SG, Roden DM, George AL Jr, Goldstein SA (2000) A common polymorphism associated with antibiotic-induced cardiac arrhythmia. Proc Natl Acad Sci U S A 97:10613-10618. CrossRef Medline

Shibata R, Misonou H, Campomanes CR, Anderson AE, Schrader LA, Doliveira LC, Carroll KI, Sweatt JD, Rhodes KJ, Trimmer JS (2003) A fundamental role for KChIPs in determining the molecular properties and trafficking of Kv4.2 potassium channels. J Biol Chem 278:36445-36454. CrossRef Medline

Strange K, Christensen M, Morrison R (2007) Primary culture of Caenorhabditis elegans developing embryo cells for electrophysiological, cell biological and molecular studies. Nat Protoc 2:1003-1012. CrossRef Medline

Tang YQ, Liang P, Zhou J, Lu Y, Lei L, Bian X, Wang K (2013) Auxiliary KChIP4a suppresses A-type K+ current through endoplasmic reticulum (ER) retention and promoting closed-state inactivation of $\mathrm{Kv} 4$ channels. J Biol Chem 288:14727-14741. CrossRef Medline

Thomsen MB, Sosunov EA, Anyukhovsky EP, Ozgen N, Boyden PA, Rosen MR (2009) Deleting the accessory subunit KChIP2 results in loss of $\mathrm{I}(\mathrm{to}, \mathrm{f})$ and increased $\mathrm{I}(\mathrm{K}$,slow) that maintains normal action potential configuration. Heart Rhythm 6:370-377. CrossRef Medline

Wang HG, He XP, Li Q, Madison RD, Moore SD, McNamara JO, Pitt GS (2013) The auxiliary subunit KChIP2 is an essential regulator of homeostatic excitability. J Biol Chem 288:13258-13268. CrossRef Medline

Weinshenker D, Wei A, Salkoff L, Thomas JH (1999) Block of an ether-ago-go-like $\mathrm{K}(+)$ channel by imipramine rescues egl-2 excitation defects in Caenorhabditis elegans. J Neurosci 19:9831-9840. Medline

Wu MN, Joiner WJ, Dean T, Yue Z, Smith CJ, Chen D, Hoshi T, Sehgal A, Koh K (2010) SLEEPLESS, a Ly-6/neurotoxin family member, regulates the levels, localization and activity of Shaker. Nat Neurosci 13:69-75. CrossRef Medline

Yin JA, Liu XJ, Yuan J, Jiang J, Cai SQ (2014) Longevity manipulations differentially affect serotonin/dopamine level and behavioral deterioration in aging Caenorhabditis elegans. J Neurosci 34:3947-3958. CrossRef Medline

Yuan A, Dourado M, Butler A, Walton N, Wei A, Salkoff L (2000) SLO-2, a $\mathrm{K}+$ channel with an unusual Cl- dependence. Nat Neurosci 3:771-779. CrossRef Medline 